\title{
MECHANISMS FOR FATIGUE OF MICRON-SCALE SILICON STRUCTURAL FILMS
}

Daan Hein Alsem ${ }^{1,2,3}$ Olivier N. Pierron ${ }^{4}$, Eric A. Stach ${ }^{5}$, Christopher L. Muhlstein ${ }^{6}$ and Robert O. Ritchie ${ }^{1,2, *}$

1. Department of Materials Science and Engineering, University of California, Berkeley, CA 94720

2. Materials Sciences Division, Lawrence Berkeley National Laboratory, Berkeley, CA 94720

3. National Center for Electron Microscopy, Lawrence Berkeley National Laboratory, Berkeley, CA 94720

4. Qualcomm MEMS Technologies Inc., San Jose, CA 95134

${ }^{5}$ School of Materials Engineering, Purdue University, West Lafayette, IN 47907

6. Department of Materials Science and Engineering, The Pennsylvania State University, University Park, PA 16802

* Hearst Memorial Mining Building, University of California, Berkeley, CA 94720-1760, tel: (510) 486-5798, fax: (510) 643-5792, e-mail: RORitchie@lbl.gov

\section{Summary}

Although bulk silicon is not susceptible to fatigue, micron-scale silicon is. Several mechanisms have been proposed to explain this surprising behavior although the issue remains contentious. Here we describe published fatigue results for micron-scale thin silicon films and find that in general they display similar trends, in that lower cyclic stresses result in larger number of cycles to failure in stress-lifetime data. We further show that one of two classes of mechanisms is invariably proposed to explain the phenomenon. The first class attributes fatigue to a surface effect caused by subcritical (stable) cracking in the silicon-oxide layer, e.g., reaction-layer fatigue; the second class proposes that subcritical cracking in the silicon itself is the cause of fatigue in Si films. It is our contention that results to date from single and poly crystalline silicon fatigue studies provide no convincing experimental evidence to support subcritical cracking in the silicon. Conversely, the reaction-layer 
mechanism is consistent with existing experimental results, and moreover provides a rational explanation for the marked difference in fatigue behavior of bulk and micron-scale silicon.

\section{Introduction to fatigue of micron-scale silicon}

The long-term durability study of micron-scale silicon structures is of particular importance for microelectromechanical systems (MEMS) developers, who heavily use silicon as a structural material. Silicon, however, is quite brittle and subject to several reliability concerns - most importantly, stiction ${ }^{[1,2]}$, wear ${ }^{[1,3]}$ and fatigue - that can limit the utility of silicon MEMS devices in commercial and defense applications. Currently, there are many commercial silicon-based MEMS devices that are subjected to various environments and forms of periodic loading, sometimes at very high frequency, such as resonators found in both radio frequency as well as MEMS sensor applications. Although the maximum operating stresses in these devices are designed to be lower than the fracture stress, delayed failure under cyclic loading may occur for devices that accumulate a large number of cycles over their lifetime. Because the surface-to-volume ratio of the structural silicon in these devices is very large, traditional failure models developed for materials at the bulk scale cannot always be relied upon to accurately predict behavior, because inherently new physical mechanisms may be operative. Indeed, it is clear that at these size-scales, surface effects can control the mechanical properties.

The fatigue behavior of silicon films was first reported in the early 1990s after the testing of micron-scale silicon structures became possible with emerging MEMS technologies. It was quickly discovered by Connally and Brown ${ }^{[4]}$ that the delayed failure under cyclic loading for micron-scale silicon differed from the macroscale behavior of the material. Silicon is a brittle 
material that does not exhibit any dislocation activity at low homologous temperatures ${ }^{[5]}$, any extrinsic toughening mechanisms ${ }^{[6]}$, or any evidence of susceptibility to environmentallyassisted cracking ${ }^{[7-9]}$. Based on this information and knowledge of macro-scale fatigue mechanisms ${ }^{[10]}$, silicon should not fatigue at room temperature and thus the findings of Connally and Brown were both surprising and unexpected. Since that time, there have been several attempts to provide a mechanism capable of explaining this unique fatigue behavior of silicon films.

As shown in this review, two main classes of mechanisms for fatigue degradation of silicon films currently prevail the literature. The first class of mechanisms asserts that the fatigue degradation process is a surface phenomenon, in which fatigue of silicon thin films is attributed to a process of subcritical cracking within the surface oxide layer (ref. ${ }^{[11,12]}$ ). Cyclic stress-induced, thickened silicon-oxide reaction layers allow for the initiation and growth of cracks within the layer via environmentally- and cyclically-assisted cracking processes until they reach the critical length where unstable fracture occurs. The second class of silicon fatigue mechanisms that have been proposed asserts that fatigue damage evolves due to subcritical cracking of the silicon itself, rather than the oxide reaction-layer (ref. ${ }^{[13]}$ ). Several causes for this type of crack growth in silicon have been suggested: (i) crack growth due to the cyclic compression fatigue aided by a wedging effect of debris or the oxidized surface inside the crack; (ii) crack growth occurring by dislocation activity, causing either crack-tip blunting, or crack-tip blunting followed by sharpening (similar to fatigue in ductile materials); or (iii) crack growth caused by grain-boundary deformation by means of plastic (shear) deformation in the thin amorphous region of a grain boundary that intersects the free surface of the film ${ }^{[13]}$. Here we show that based on the results of extensive experimental 
studies performed using a variety of specimen geometries and testing techniques, mechanisms involving subcritical cracking in the silicon-oxide reaction layers represent the most viable explanation for the phenomena of the fatigue of micron-scale silicon films, and moreover provide a reason why this effect is not seen in bulk silicon.

The numerous studies on both single and poly crystalline silicon are described in the following two sections, including recapitulative (normalized) stress-total lifetime $(S-N)$ graphs for fatigue in ambient air. Particular attention is given to the proposed mechanisms for the observed fatigue phenomena and the experimental evidence provided to support these different mechanisms. Details on the various micron- and submicron-scale fatigue testing devices, systems and methods used in this discipline are outlined in the Appendix.

\section{Fatigue test results and mechanisms for single-crystal silicon thin films}

In this section, we describe studies on the cyclic fatigue behavior of single-crystal (sub-) micron-scale structural silicon films. A compendium of these studies and their principal results are listed in Table 1. Factors such as loading conditions, operating frequency, and environment are shown to contribute by varying degrees to fatigue damage accumulation in thin films, with post-failure material characterization and numerical modeling providing insight for the development of micron-scale silicon fatigue mechanisms.

The micromechanical fatigue testing of silicon thin films began with the work of Connally and Brown on 2.9 and $5 \mu \mathrm{m}$ thick, single-crystal silicon films in the early $1990 \mathrm{~s}^{[4,14,15]}$. Using a notched, electrostatically-actuated resonator system (resonance frequency $\sim 12 \mathrm{kHz}$ with a 
stress ratio of $-1^{\mathrm{a}}$ ), these authors suggested that delayed failure was caused by water-induced, slow crack growth that occurred by environmentally-assisted cracking in the silica layer that forms on silicon upon exposure to oxygen. In that regard, the fatigue behavior for micronscale silicon devices did not duplicate macroscopic-scale fatigue, as results from macroscopic silicon specimens clearly show that neither fatigue-crack growth nor environmentally-assisted cracking in air or water occurs in silicon ${ }^{[8,16]}$. They further observed that the resonator's natural frequency decreased with time, which they interpreted as a measure of subcritical (stable) crack growth; the rate of this frequency change also decreased, which they suggested was associated with a reduction in crack-growth rate with increasing crack length. On the basis of these observations, they proposed that growth rates were rate-limited by the reaction rates at the crack tip or by transport of reaction species to, or from, the crack-tip region. This led them to conclude that the actual mechanism governing crack growth in micron-scale silicon devices (driven at resonance) was more complex than simply environmentally-assisted fatigue of silica ${ }^{[17]}$. Nevertheless, they strongly believed that water could accelerate or initiate crack propagation, since while the resonant frequency was observed to remain constant for specimens tested in dry air, a decrease was monitored after introducing wet air into the testing chamber. Fracture surface examination revealed merging of the pre-crack front into a planar front perpendicular to the maximum principal tensile stress, and a change in direction with propagation along $\{111\}$ low surface energy planes; they postulated that the planar front was due to environmentally-assisted fatigue of the silica layer on the silicon surface. This interpretation of the failure surface should be viewed with some caution since the extent of subcritical crack growth and coalescence of the overdriven pre-cracks in silicon cannot be

\footnotetext{
${ }^{\text {a }}$ The stress (or load) ratio $R$ is defined as the ratio of the minimum to maximum applied stress (or load).
} 
differentiated fractographically. Furthermore, their quantitative results are somewhat questionable due to the nonlinear behavior of the resonator (which complicates modeling of the system). In spite of these limitations, Connally and Brown were the first investigators to suggest that an inherently brittle material such as single-crystal silicon could undergo cyclic fatigue failure when in the form of a thin free-standing film.

Following this work, several other studies on the fatigue of silicon were conducted. TabibAzar et al. ${ }^{[18]}$ used a different resonator structure $(1.8 \mu \mathrm{m}$ thick films, resonant frequency around $6-7 \mathrm{kHz}, R=-1$ ) to correlate damage accumulation and cracking. Their experimental results consisted of measured center frequency and full width at half amplitude (FWHA) of the oscillation spectra. In all the resonators, the FWHA increased with cycling, indicating an increased amount of energy dissipated internally. The changes in FWHA were too large to be caused by thermo-elastic effects, and were therefore postulated to be caused by microcracking of the beam. However, the resonant frequency was found to increase with cycling, a result inconsistent with the decrease in stiffness associated with microcracking. Moreover, no direct observations of the mode of cracking were made.

Tsuchiya and coworkers confirmed the findings of Connally and Brown, with a study on the influence of environment on the fatigue behavior of single-crystal silicon resonators at 9 $\mathrm{kHz}$ (no silicon film thickness specified) ${ }^{[19]}$. The results of this investigation suggested that the mean fracture strength of the specimen, measured by static loading, was $\sim 17 \%$ higher than the mean strength measured by resonant vibration, implying that fatigue occurred over the short number of cycles experienced by the specimen prior to failure. Fatigue failure in air was observed after $2.9 \times 10^{7}$ cycles for a specimen initially loaded at a stress $10 \%$ lower than the cyclically measured fracture strength and $20 \%$ lower for a specimen run for $1.6 \times 10^{8}$ cycles. 
These results revealed that the longer the fatigue life, the more the fatigue damage accumulation, although again no direct observations of this damage were made. Their experimental results did show that the testing environment affected both the specimen's fracture strength and fatigue life. For high humidity environments, mean strengths were $10 \%$ lower than for low humidity environments. More recently, Tsuchiya has also shown that in air, the mean fracture strength is $70-80 \%$ of the strength in vacuo ${ }^{[20]}$. The fatigue lives were severely reduced for specimens tested in environments containing water vapor and/or oxygen (the effect of water vapor was more pronounced than the effect of oxygen). These authors attributed their findings to a mechanism involving oxidation at a crack initiation site on the silicon surface that allowed further crack growth.

Like Tsuchiya et al., Komai, Minoshima, and coworkers ${ }^{[21,22]}$ investigated the influence of water on the fatigue behavior of $30 \mu \mathrm{m}$ thick, single-crystal silicon under (near)zerotension cyclic loading $(R=0.1)$ at a frequency of $0.1 \mathrm{~Hz}$. Komai et al. reported shorter fatigue lives in water, compared to air, for a maximum stress of $3.4 \mathrm{GPa}$ (Figure 1). In addition, fatigue lives appeared to decrease with increasing immersion time in water prior to testing. Atomic force microscopy (AFM) images of specimens cycled in air did not reveal any nanometer-scale fatigue damage on the specimen surface after a maximum of $5 \times 10^{4}$ cycles. However, nanoscale grooves were observed on fatigued specimens in water using AFM with a sharp tip ( $\sim 5 \mathrm{~nm}$ radius). The orientation of these grooves was not perpendicular to the maximum principal stress, but rather about $70^{\circ}$ to the $\langle 112>$ longitudinal direction, probably corresponding to cracking along a $\{111\}$ plane. Fracture surface examination of the same sample revealed a crack-initiation site associated with a $300 \mathrm{~nm}$ deep defect. Komai et al. 
concluded that a synergistic mechanism of fatigue loading and water environment caused a nanometer-scale crack to develop on a $\{111\}$ plane and to gradually grow to criticality.

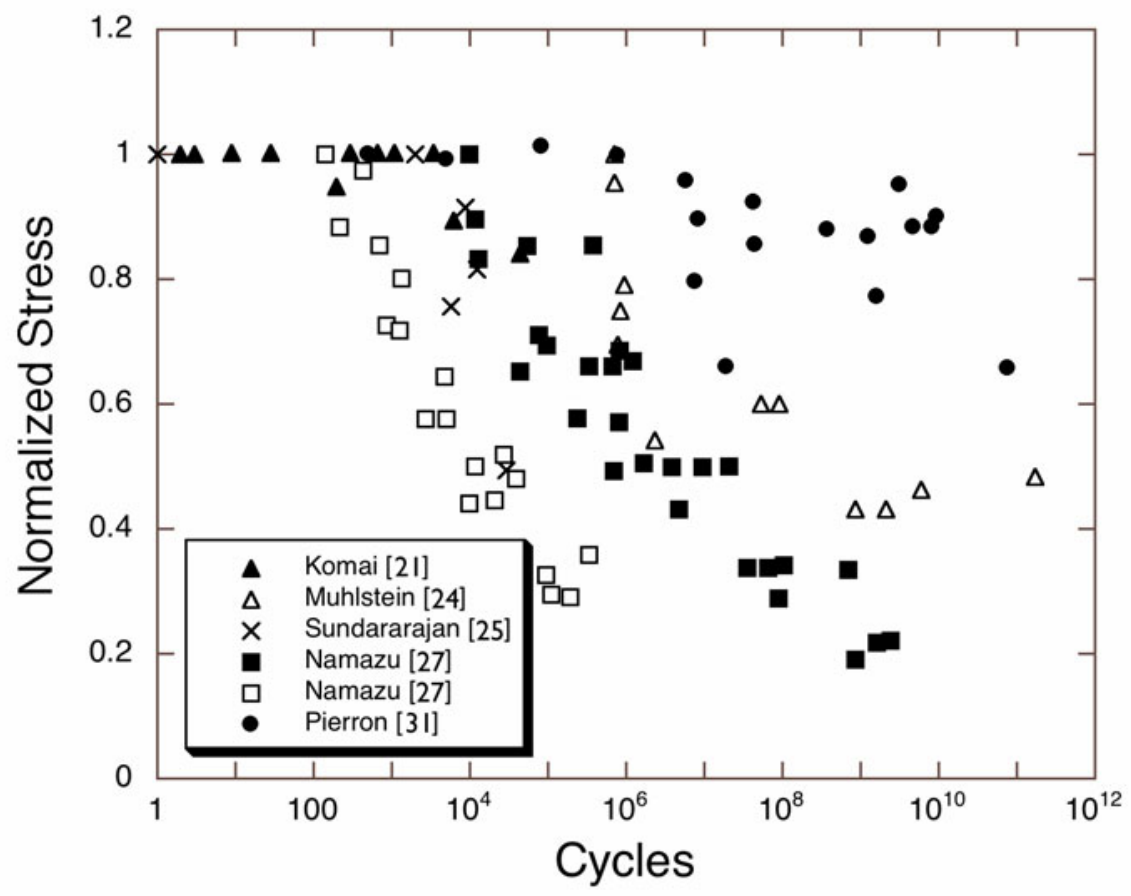

Figure 1: Normalized applied maximum stress vs. number of cycles to failure $(S-N)$ curve for the cyclic fatigue of single-crystal silicon in ambient air taken from the available literature. The stress values are normalized with respect to the stress from the test in that particular study that was run at the lowest number of cycles (and therefore in all but one case also with the test run at the highest stress). For the data from Namazu ${ }^{[27]}$ : the open squares are tests in bending and the closed squares are tests in tension.

Ando et al. ${ }^{[23]}$ also measured tensile loading fatigue effects at $R=0.1$ in laboratory air (at $10 \mathrm{~Hz})$ as well as the fracture strength of $5 \mu \mathrm{m}$ thick silicon thin films. The average quasistatic fracture strain was calculated to be $4.25 \%$ in the $\langle 100\rangle$ direction and $3.4 \%$ in the $<110\rangle$ direction, corresponding to fracture stresses of 5.52 and $5.74 \mathrm{GPa}$, respectively. Under displacement-controlled cyclic actuation, failure occurred after a small number of cycles 
(ranging from $10^{2}$ to $10^{5}$ cycles) for maximum applied strains near the mean fracture strain. However, failure was not observed until $10^{6}$ cycles or more for applied maximum strains below $75-80 \%$ of the average fracture strain. Throughout these displacement-controlled experiments, no decrease in applied load (load resolution $\pm 1 \mathrm{mN}$ ) was observed during cyclic actuation (maximum load $\sim 100 \mathrm{mN}$ ), implying that the decrease in stiffness was less than $1 \%$ before fatigue failure occurred.
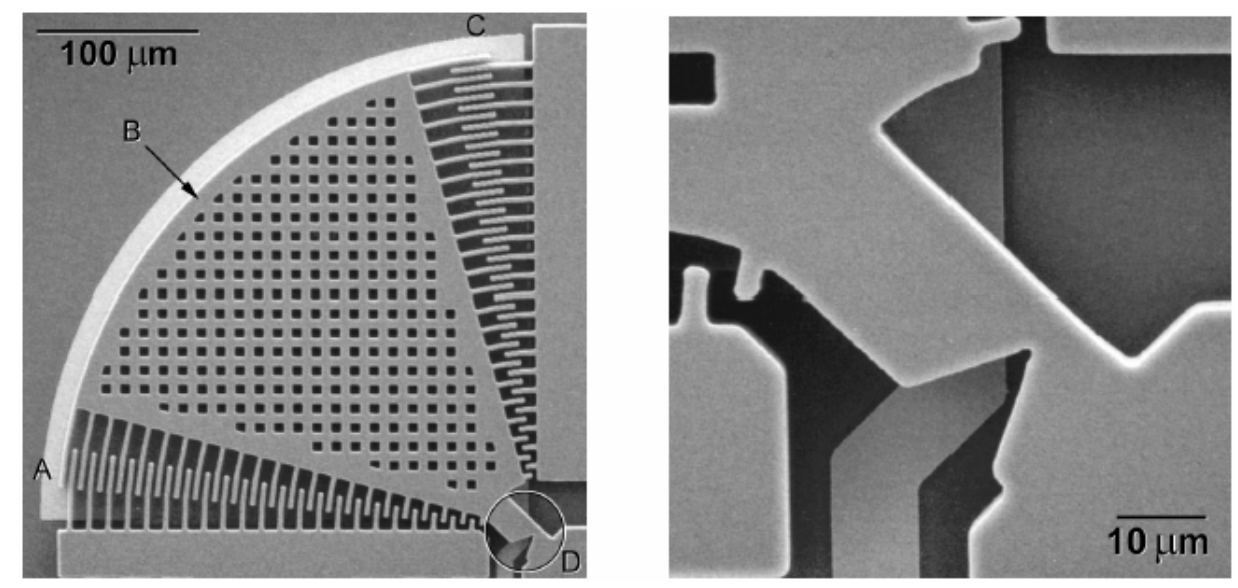

Figure 2: Scanning electron micrographs of resonator stress-life fatigue characterization structure. The electrostatic comb drive actuator (A), resonant mass (B), capacitive displacement transducer comb (C), and notched cantilever-beam specimen (D) are shown in an overview on the left. A detail of the notched beam is shown on the right. ${ }^{[24]}$

Following up on Brown's earlier work, Muhlstein, Brown, and Ritchie ${ }^{[24]}$ generated stress-life $(S-N)$ fatigue curves on $20-\mu \mathrm{m}$ thick single-crystal silicon films under fully reversed loading conditions $(R=-1)$ using a fatigue characterization resonator structure (Figure 2) operating in room temperature air at $50 \pm 2 \%$ relative humidity $(\mathrm{RH})$ (Figure 1). The fatigue life increased from less than $10^{6}$ cycles to more than $10^{11}$ cycles when the stress amplitude was decreased from 9 to $4 \mathrm{GPa}$, with no significant effect of frequency (40 vs. $50 \mathrm{kHz}$ ). The 
resonant frequency was observed to decrease monotonically during cycling, suggesting the failure of the silicon thin films occurred after progressive accumulation of damage. Moreover, the longer the life of the specimen, the larger the total decrease in resonant frequency (up to a $25 \mathrm{~Hz}$ decrease was observed), again consistent with the notion of damage accumulation. Fracture surface examination revealed a smooth $\{110\}$ crack path, corresponding to the plane of maximum tensile stress for long-life fatigue specimens, as distinct from the $\{111\}$ paths observed for single-cycle overload fracture. The authors concluded that a mechanism other than normal $\{111\}$ cleavage was active during high-cycle fatigue of silicon thin films.

Sundurarajan and Bhushan ${ }^{[25]}$ were the first to determine the fatigue behavior of nanometer-scale (255 $\mathrm{nm}$ thick) single-crystal silicon by collecting $S-N$ data (Figure 1), as well as the Young's modulus, fracture stress and an estimate of the fracture toughness. The single-cycle bending strength was calculated to be $17.9 \pm 3 \mathrm{GPa}$, a high value attributed to the nanometer-sized specimen. Delayed failure was observed at stresses as low as $6.2 \mathrm{GPa}$ after more than $3 \times 10^{4}$ cycles. Scanning electron micrographs suggested that the beams failed by cleavage fracture with a facetted surface for the single-cycle fractured beams, indicating a high-energy fracture on a $\{100\}$ plane in combination with low-energy cleavage on $\{111\}$ planes. For the fatigued specimens, smooth fracture surfaces were found, without facets or irregularities. These authors proposed that fracture occurred by low-energy cleavage on $\{111\}$ planes, with a fatigue mechanism similar to environmentally-assisted cracking.

A very large set of $S-N$ data was generated by Namazu and Isono at room temperature for nanometer-scale (255 $\mathrm{nm}$ thick) as well as micron-scale (2 to $25 \mu \mathrm{m}$ thick) single-crystal silicon specimens (Figure 1) ${ }^{[26,27]}$. Specimens were run in bending as well as tension, with a positive stress ratio $(R)$ and maximum applied cyclic stresses ranging from $10 \%$ to $90 \%$ of the 
average fracture strength; the loading frequency was varied from 10 to $450 \mathrm{~Hz}$. In bending fatigue tests, the number of cycles to failure increased from $10^{2}-10^{3}$ to $10^{5}-10^{6}$ cycles as the peak stress decreased from 90 to $30 \%$ of the fracture strength, regardless of the size of the specimen. In tensile fatigue tests, the number of cycles to failure increased from $10^{4}-10^{5}$ cycles to $10^{9}-10^{10}$ cycles as the peak stress decreased from 90 to $20 \%$ of the fracture strength, again regardless of specimen size. No significant influence of the frequency was observed on the number of cycles to failure.

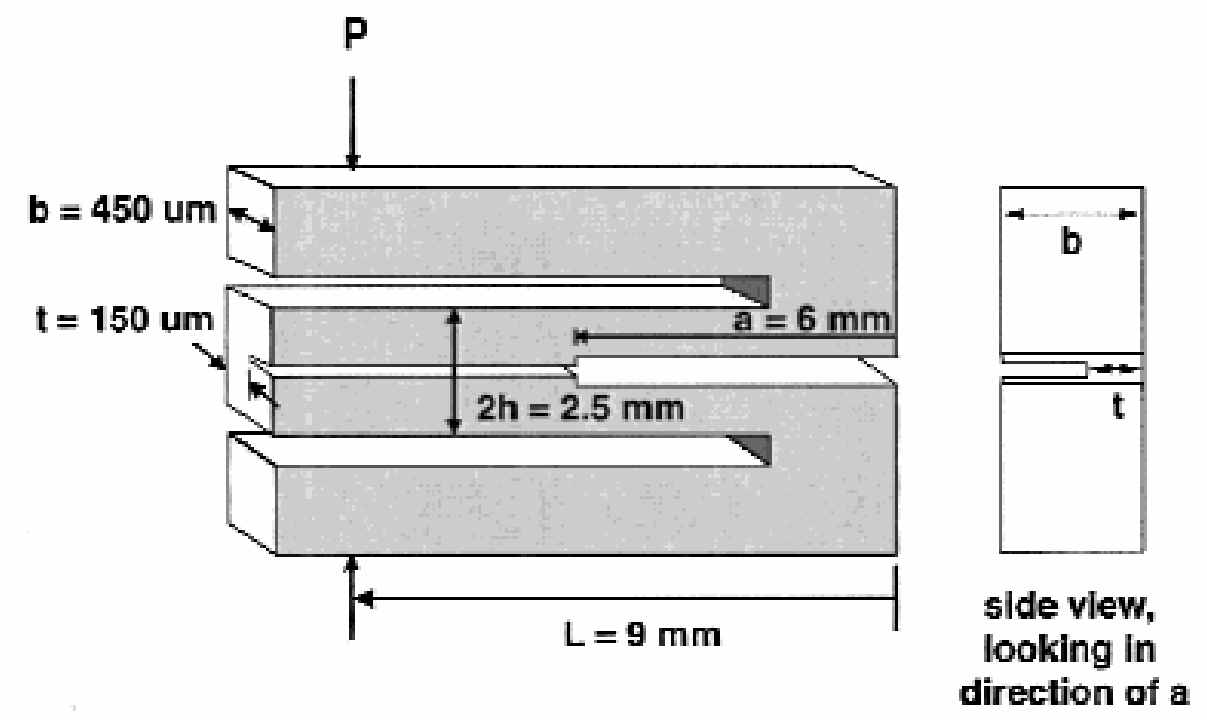

Figure 3: Schematic illustration of the compression-loaded double cantilever beam specimen. Specimen height is $7.6 \mathrm{~mm}$ with a length of $12 \mathrm{~mm} .^{[28]}$

Dauskardt, Kenny, Fitzgerald, and coworkers investigated subcritical crack growth in precracked, $150 \mu \mathrm{m}$ thick, single-crystal silicon specimens ${ }^{[28,29]}$. A discrete step-like crackgrowth process was observed under monotonic loading. As the load was increased, unstable fracture occurred when the stress intensity, $K_{\mathrm{I}}$, approached the toughness of the material (measured at $K_{\mathrm{Ic}}=1.15 \pm 0.08 \mathrm{MPa} \cdot \mathrm{m}^{1 / 2}$ ). Due to the geometry of the specimen, $K_{\mathrm{I}}$ decreased 
with crack extension, leading to crack arrest, with the process repeating itself with further loading. Limited evidence of continuous and subcritical crack growth was noted under constant-load conditions, for an applied stress intensity $\left(1.05 \mathrm{MPa} \cdot \mathrm{m}^{1 / 2}\right)$ close to the toughness of the material. The corresponding $v-K_{\mathrm{I}}$ curves (crack velocity vs. applied stress intensity) suggested that subcritical cracking only occurred for $0.9 K_{\text {Ic }}<K_{\mathrm{I}}<0.98 K_{\text {Ic }}$, with a crackgrowth rate exponent, $n$, higher than 100 (fitting the results to $v=\mathrm{C} K^{\mathrm{n}}$, where $C$ and $n$ are constants). Because subcritical crack growth only occurs in the regime where the applied $K_{I}$ approaches the $K_{I c}$ value (region III in $v$ - $K_{I}$ curves where the crack velocity outpaces transport of the environmental species), the authors concluded that environmentally-assisted subcritical cracking is absent in monotonically loaded micron-scale silicon.

In addition to these quasi-static tests, Dauskardt and co-workers also conducted fatiguecrack growth tests where they cyclically loaded specimens at $20 \mathrm{~Hz}$ with nominal stress ratio of $R=0.1$. Akin to monotonic loading conditions, the crack-growth behavior was observed to be step-like in nature, with unstable crack extension when the maximum applied stress intensity reached the fracture toughness. Under decreasing $K$ conditions, cracks were observed to arrest. The resulting growth rate versus $K_{\max }$ curves were similar to the curves obtained under monotonic loading, which suggested that the relevant crack-growth process in single-crystal silicon was not true cyclic fatigue. This conclusion was further supported by the fact that fracture surfaces under cyclic and monotonic loading were similar. The authors also conclude that fatigue mechanisms involving cracking of a surface reaction-layer would be a viable mechanism.

Based on the known correlation between damage accumulation in a resonator and its resonance frequency, Koskenvuori et al. ${ }^{[30]}$ investigated the long-term stability of micro- 
resonators in air and vacuum. Four $10 \mu \mathrm{m}$ thick, single-crystal specimens were tested under resonance for $4.7 \times 10^{13}$ cycles: two in vacuum $(P \sim 5 \mathrm{mbar})$ and two in air $\left(30^{\circ} \mathrm{C}, 20-35 \%\right.$ $\mathrm{RH})$. The specimens tested in vacuo maintained their initial frequency within $1 \mathrm{ppm}$ (corresponding to a $13 \mathrm{~Hz}$ decrease in resonant frequency) after $4.7 \times 10^{13}$ cycles. In contrast, the resonant frequency $\left(f_{0}\right)$ of the specimens tested in air continuously decreased to a total shift of 40-70 ppm from the initial $f_{0}$ (i.e., a 550-950 Hz decrease) after $4.7 \times 10^{13}$ cycles. In addition, a clear correlation between relative humidity and resonant frequency was recorded ( $f_{0}$ increasing with decreasing $\left.\mathrm{RH}\right)$. The authors interpreted this result as increased water adsorption at the surface with increasing $\mathrm{RH}$. They further concluded that the resonator stability could be severely affected by water contamination of the resonator surface due to the humidity in ambient air. This study provides additional evidence that silicon films degrade over time in air and that this degradation is significantly less in low vacuum.

Most recently Pierron and Muhlstein ${ }^{[31]}$ measured the effect of the service environment on the fatigue resistance of $10 \mu \mathrm{m}$ thick, single-crystal silicon resonators (resonant frequencies $\sim 40 \mathrm{kHz}$; stress ratio of $R=-1$, test sample similar in design to Figure 2). $S-N$ data, incorporated in Figure 1, demonstrated the fatigue susceptibility of these films in ambient air $\left(30^{\circ} \mathrm{C}, 50 \% \mathrm{RH}\right)$. The fatigue life in air increased markedly from $5.0 \times 10^{2}$ to 7.5 $\times 10^{10}$ cycles as the applied stress was reduced from 3.4 to $2.2 \mathrm{GPa}$. In contrast with the data collected in air, none of the specimens tested in medium vacuum (10-40 Pa) at stress amplitudes between 2.5 and 3.0 GPa failed, at least up to $\sim 10^{10}$ cycles. Additionally, most specimens tested in air, at stresses higher than $3 \mathrm{GPa}$, failed before $10^{8}$ cycles, whereas for two specimens tested in vacuum, lives exceeded $10^{9}$ cycles. Additionally, damage accumulation rates were calculated by monitoring the natural frequency of the resonator 


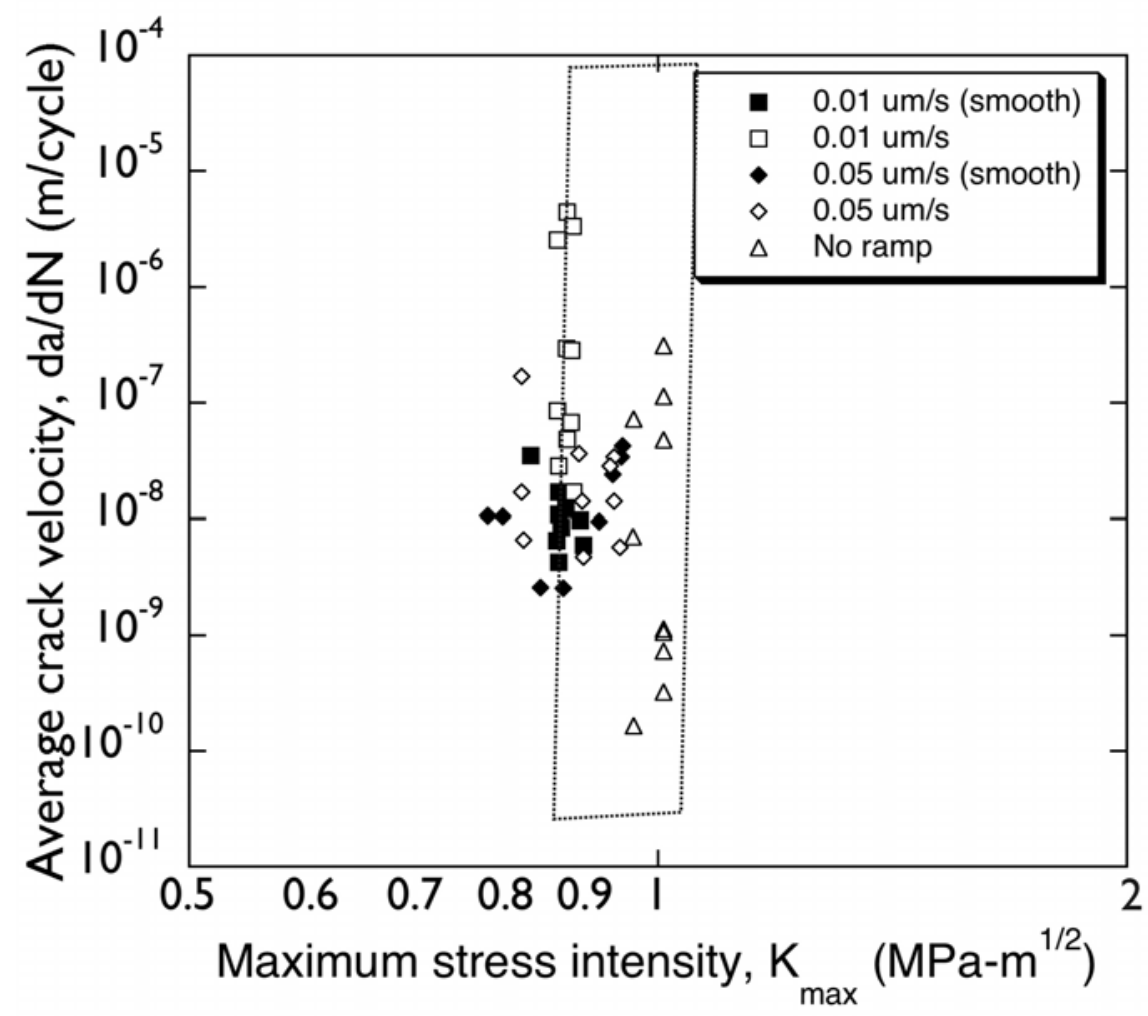

Figure 4: Fatigue-crack growth data, d $a / d N$ vs. $K_{\max }$, in $150 \mu \mathrm{m}$ thick single-crystal silicon (from different load ramps) are compared for cyclic and static fatigue tests. The area marked by the dotted line shows static fatigue test results in $50 \%$ relative humidity. ${ }^{[29]}$

during cycling. The surrounding humidity was found to have a dramatic effect on the damage accumulation rate that was one order of magnitude larger at $50 \%$, as compared to $25 \%, \mathrm{RH}$ (Figure 5). In contrast, virtually no damage was observed in a medium vacuum environment with a bake performed prior to testing. Fatigue was attributed to the reaction-layer fatigue mechanism [11], i.e., to moisture-assisted subcritical cracking in a cyclic stress-assisted thickened surface oxide layer. This mechanism will be discussed in more detail in the next section. 


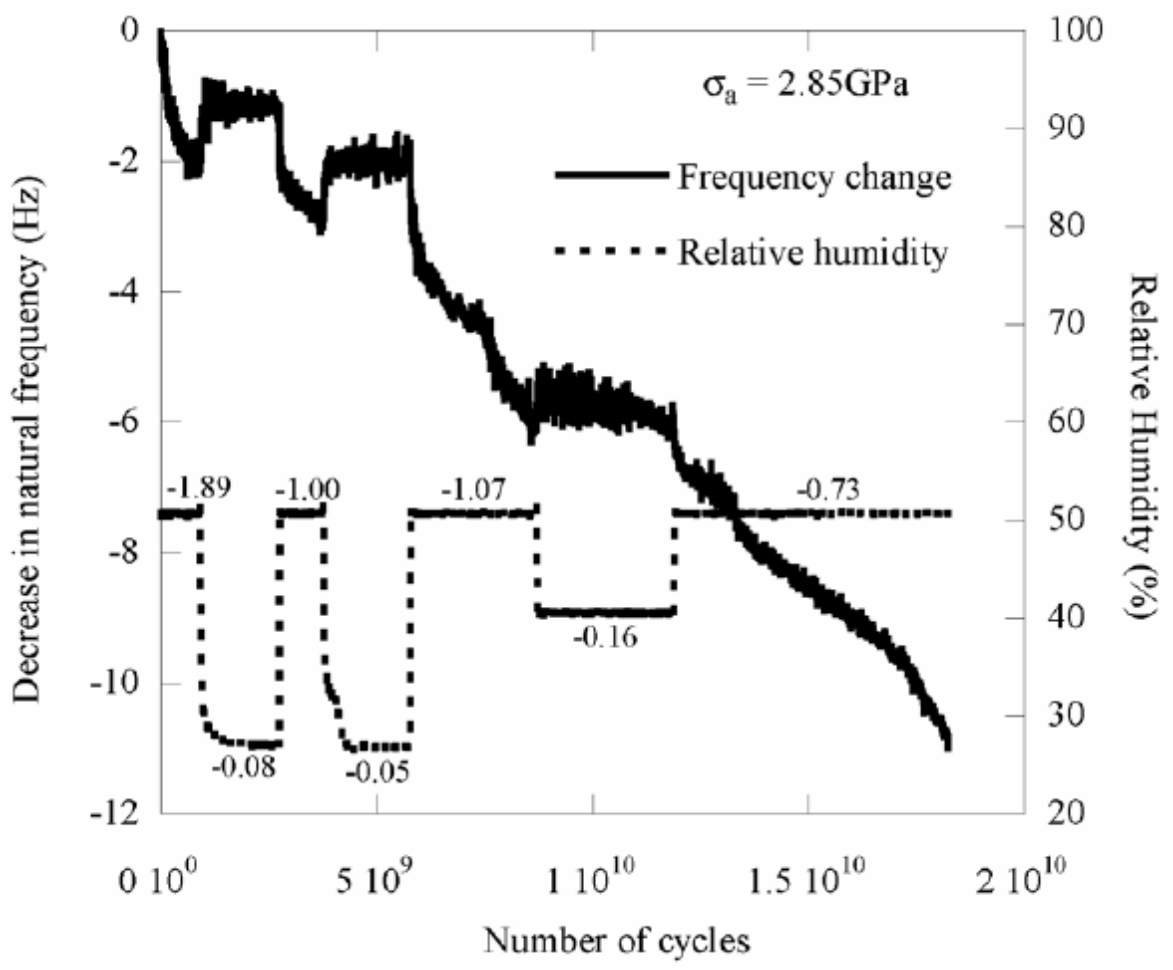

Figure 5: Decrease in resonant frequency, $f_{0}$, during cycling at constant stress amplitude $(2.85$ $\mathrm{GPa})$ in air $\left(30^{\circ} \mathrm{C}\right)$ at various successive relative humidity levels: 50, 25, 50, 25, 50, 40, and $50 \% \mathrm{RH}$. The numbers near the relative-humidity line indicate the average decrease in $f_{0}$ per $10^{9}$ cycles for the particular humidity value. ${ }^{[31]}$ 
Table 1: Summary of fatigue testing of single-crystal silicon thin films from 1991 to 2006. The upwards and downwards pointing arrow-symbols refer respectively to increases and decreases.

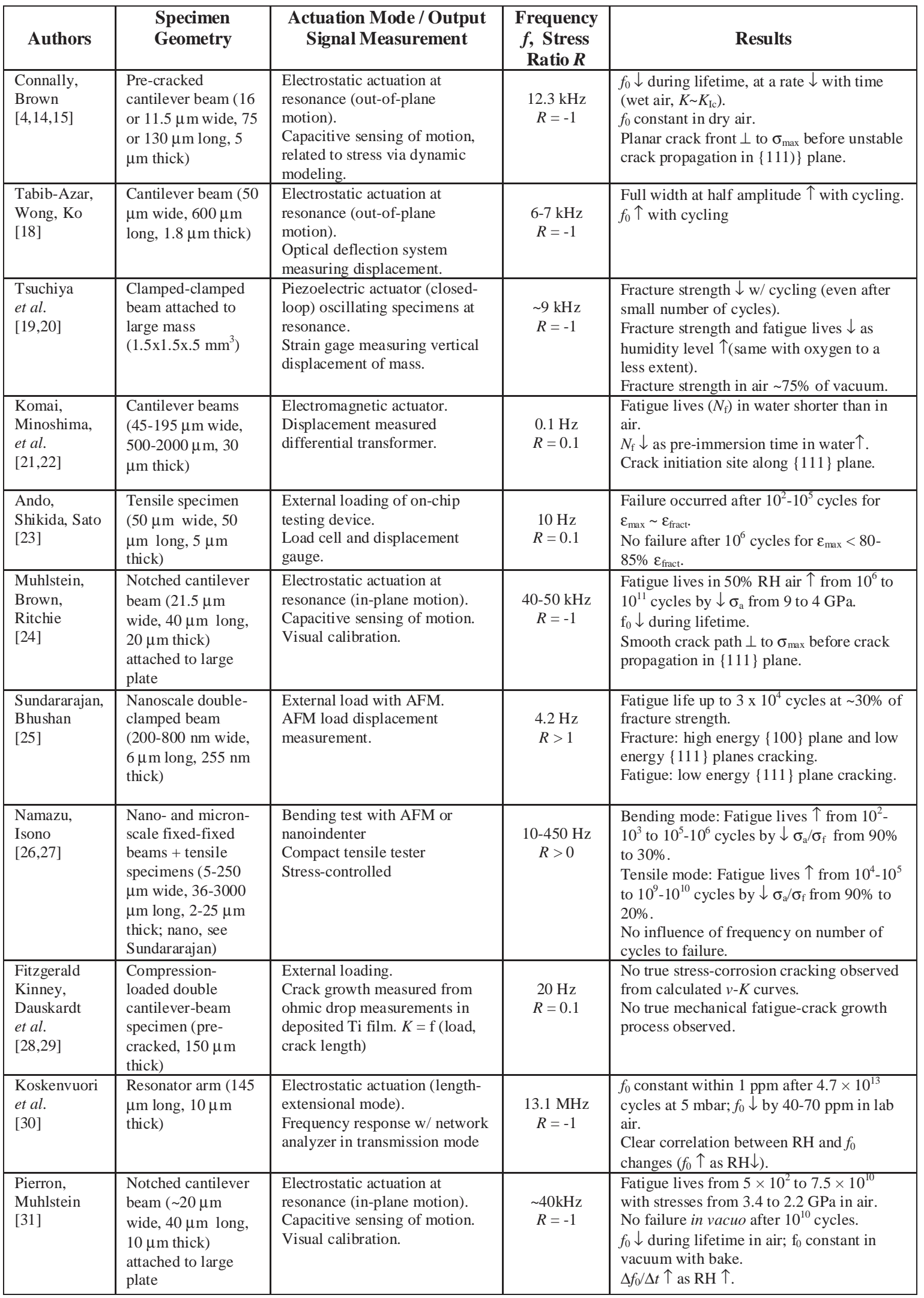




\section{Fatigue test results and mechanisms for polycrystalline silicon thin films}

After the initial publications on fatigue in single-crystal silicon films, results on polycrystalline silicon structural thin films soon became available. These are reviewed below, again in chronological order, with a compendium listed in Table 2. In general, they demonstrate that factors such loading conditions, operating frequency and, most importantly, environment have effects that are similar to those described above for single-crystal silicon.

Early work on fatigue in polycrystalline silicon (polysilicon) films, by Van Arsdell and Brown ${ }^{[32]}$, used a polysilicon fatigue testing resonator (resonance frequency $\sim 40 \mathrm{kHz}$, stress ratio $R=-1$, similar to Figure 2), comprising a $2 \mu \mathrm{m}$ thick, pre-cracked cantilever-beam sample. Akin to studies on single-crystal silicon thin films, results showed a susceptibility of micron-scale polysilicon to delayed fracture by fatigue. In wet air, a decrease in resonant frequency of the pre-cracked specimens was observed and interpreted as crack growth (the calculated maximum applied stress intensity was $\sim 0.3 \mathrm{MPa} . \mathrm{m}^{1 / 2}$ ); in dry air, the resonant frequency did not change significantly. To confirm that the decrease in frequency was related to damage at the crack tip, uncracked (control) specimens were tested and showed no resonant frequency changes in wet air. Based on these studies, the authors concluded that polysilicon thin films were susceptible to subcritical crack growth via an environmentally-assisted cracking mechanism. Fracture surface examination suggested a transgranular crack path, which was considered as further proof of environmentally-assisted cracking involving the native oxide film rather than the polysilicon itself. The authors argued that the environmentally-assisted cracking mechanism in the oxide would repeat itself, as the reduced diffusion path for further oxidation (due to cracking) would facilitate further growth of the oxide film at the crack tip. They referred to this as "static fatigue", as it only seemed to 
depend on the environment and stress level, even though no experimental data were obtained under static loading. This mechanism excludes the effect of the number of load cycles on the observed fatigue behavior; this in contrast to the reaction-layer mechanism, which also attributes the fatigue effect to cracking in the surface oxide layer, as discussed later in this section.

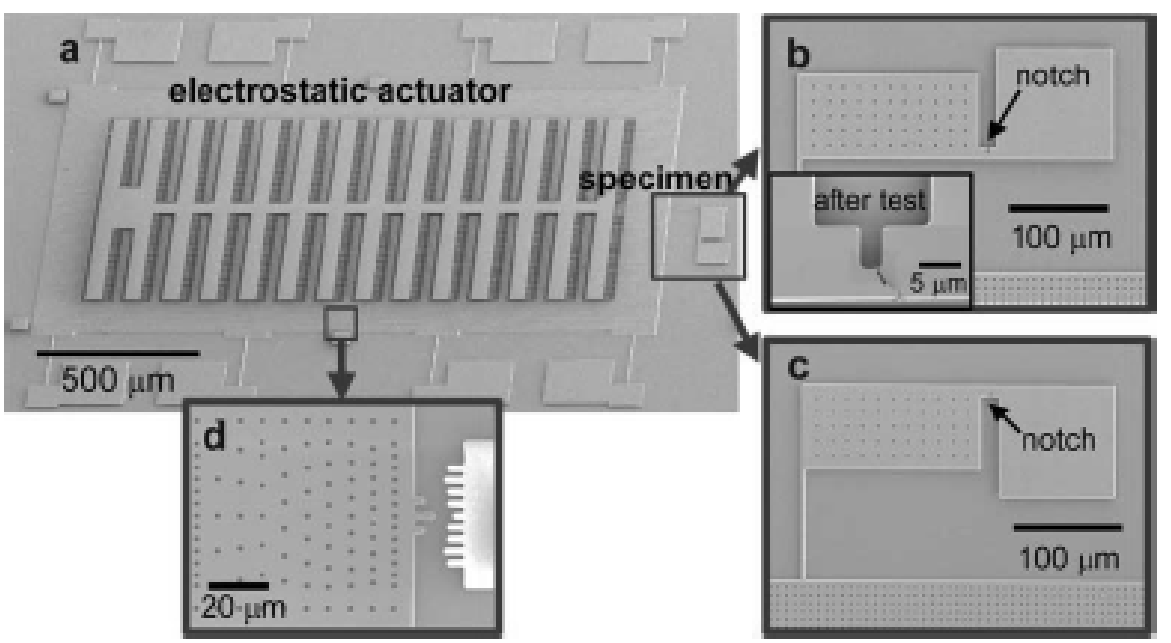

Figure 6: Scanning electron microscopy (SEM) images of a micromachined device for measuring bend strength and fatigue resistance. (a) The electrostatic comb-drive actuator integrated with the fracture mechanics specimen. $(b, c)$ Higher magnification rotated images of two single edge-notched fatigue specimens that can be integrated with the actuator; the inset in (b) shows the notch area after testing. (d) Higher magnification rotated image of the measurement scale used for optical displacement detection. ${ }^{[36]}$

Completely different mechanisms for the fatigue of micron-scale polysilicon were suggested by Kahn, Ballarini, Heuer and coworkers ${ }^{[13,33-35]}$, based on results from specimens (Figure 6) tested at varying stress ratios $(-3<R<0.5)$ in laboratory air and in a medium vacuum ( $8 \mathrm{~Pa}$ pressure). Compared to average monotonic strengths for boron-doped and undoped polysilicon specimens of, respectively, 4.1 and $4.9 \mathrm{GPa}$, the mean strengths of these 
specimens driven at resonance $(10 \mathrm{kHz})$ and quickly ramped ( 2000 to $10^{5}$ cycles) to failure was 3.2 and $4.1 \mathrm{GPa}$, implying a significant decrease in strength due to short-time $(<10 \mathrm{sec})$ cycling. ${ }^{\text {b }}$ High-cycle fatigue failure was observed in air after $\sim 10^{9}$ cycles at a maximum tensile stress of roughly half the monotonic strength. Fracture surface examination revealed a semi-circular "mirror" localized along the thickness of the specimen; this is typical of brittle fracture and characteristically surrounds a crack-initiating flaw. Kahn et al. claimed that fatigue crack initiation and growth occurred during cyclic loading in both air and vacuum, although the process was faster in air. They also suggested that mechanical damage could occur during the tensile-compression cycles, specifically in the form of microcracks. This represented a purely mechanical mechanism for the fatigue behavior of silicon thin films via subcritical cracking of the silicon itself. The notion of mechanical damage in silicon was preferred by Kahn et al. to an environmentally-assisted cracking because they could not observe static fatigue, as suggested by Van Arsdell and Brown ${ }^{[32]}$, in their silicon thin films. Using pre-cracked, doubly-clamped 3 and $3.7 \mu \mathrm{m}$ thick silicon beams, with residual tensile stresses $\sim 50 \mathrm{MPa}$, no subcritical crack growth was observed under sustained (non-cyclic) loading (constant stress of $3.6 \mathrm{GPa}$ ) in laboratory air or wet $(90 \% \mathrm{RH})$ air. These authors further found that the low-cycle fatigue strength of the electrostatically-actuated single edgenotched micro-specimens was affected more by the stress ratio (or equivalently by the maximum compressive stress) than by the environment ${ }^{[34]}$. On the basis of this, they concluded that the fatigue mechanism for silicon thin films was strongly affected by the compressive portion of the loading cycle, which they reasoned could either create a micro-

\footnotetext{
bThe term "low-cycle fatigue" can be used here as these results refer to a test in which the stress amplitude is ramped until failure while the specimen is resonating. Most $S / N$ fatigue tests of thin-film silicon, however, are carried out under "high-cycle fatigue" conditions, where high-cycle, nominally constant amplitude cycling is performed until specimen failure, as described in the Appendix.
} 
crack at the surface due to wedging on surface asperities, and allow further crack growth due to a mechanism similar to far-field cyclic compression fatigue of brittle ceramics ${ }^{[36]}$. They also investigated the high-cycle $\left(10^{4}-3 \times 10^{8}\right.$ cycles $)$ fatigue behavior in air and vacuum, and found no fatigue failures in a medium vacuum ${ }^{[34]}$, from which they concluded that ambient air exacerbated the cyclic compression fatigue mechanism. To account for their observations, Kahn et al. postulated that thickened surface oxide on newly formed crack surfaces in air could cause wedging effects that would create additional subcritical cracking (Figure 7), or that wear debris formed in vacuum could prevent crack closure and therefore decrease crackdriving force and growth (Figure 8) ${ }^{[35]}$.

The feasibility of this latter mechanism, i.e., that surface debris and/or oxidation can induce "cantilever effects" to drive the crack, has been recently questioned by Pierron and Muhlstein ${ }^{[37]}$. Utilizing a fracture-mechanics based finite-element model, they calculated the crack-opening profile and the driving force for advance of wedged cracks, and found that in compression, such wedges do not cause an increase of the magnitude of the stress-intensity factor. It is thus unlikely that this mechanism contributes significantly to the fatigue of silicon thin films. Furthermore, arguments based on the role of compressive loading fail to account for observations of fatigue failure in silicon films under cyclic tension loading (i.e., at $R \geq 0$ ) $[13,21-23,25-29,33-35]$.

The effect of mean stress and stress amplitude on the low-cycle fatigue of $5.7 \mu \mathrm{m}$ thick Bdoped polysilicon was studied by Kahn et al. ${ }^{[13]}$. Their results showed that for samples loaded with an increasing amplitude cyclic stress, with a positive mean stress the fracture stress was higher, whereas with negative mean stress the fracture stress was lower. They 

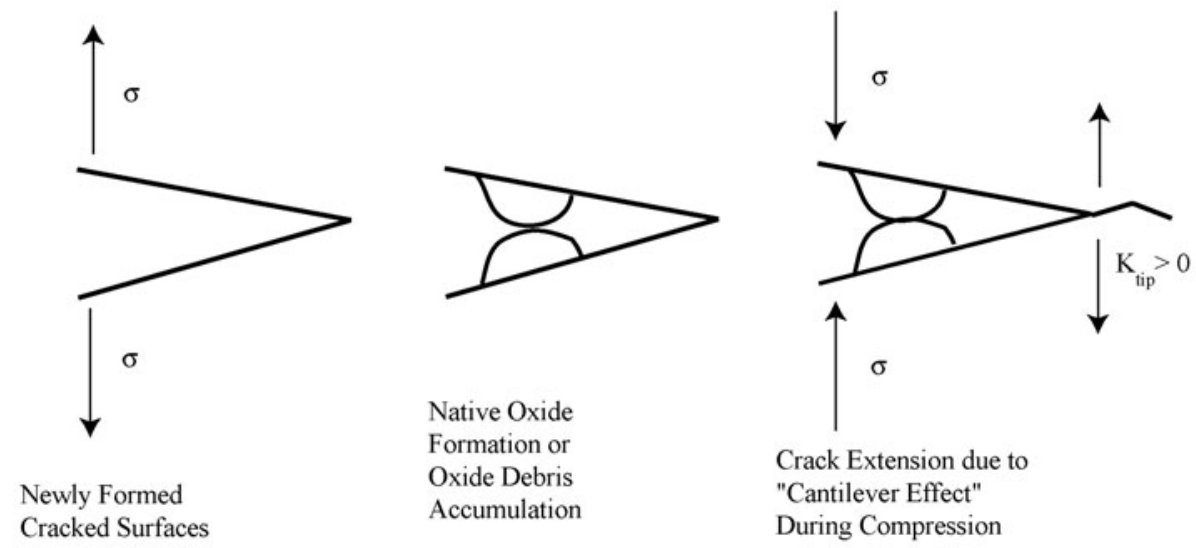

Figure 7: Schematic illustration of the mechanism, proposed by Kahn et al., to explain the influence of environment on the fatigue behavior of silicon thin films, In air, native oxide formation or oxide debris accumulation creates local wedges within the wake of newly formed crack surfaces. Under compression loading, the wedge is assumed to create a driving force for further crack extension due to a "cantilever effect". [36]

found that this was consistently the case for both Pd-coated undoped as well as B-doped specimens in air as well as medium vacuum $(10 \mathrm{~Pa})$, although the slope in the fracture stress vs. mean stress plot was different. From these data, they concluded that cyclic, and not monotonic, loading does have an influence on the fracture stress. They further showed data from tests where specimens were loaded with an applied cyclic stress, with mean stress offset, below the fracture stress, followed by a ramp to failure. For Pd-coated undoped specimens with a compressive mean stress of $2.2 \mathrm{GPa}$, the monotonic fracture strength decreased with higher cyclic amplitudes, particularly at cyclic amplitudes greater than $3 \mathrm{GPa}$. At a cyclic amplitude of $2 \mathrm{GPa}$, conversely, B-doped specimens showed an increase in monotonic strength, as compared to non-cycled specimens, independently of whether the mean stress was tensile or compressive. These low-cycle fatigue results were rationalized in terms of a "weakening and strengthening map" (Figure 9), where weakening occurs when the fatigue 
amplitude is high and the mean stress is high, or low when compressive or low when tensile.

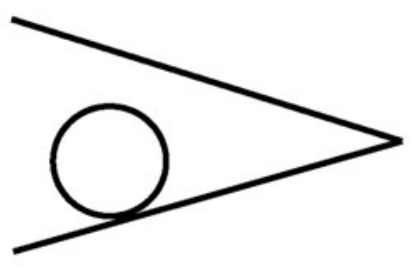

Wear debris in crack wake formed in dry air or vacuum

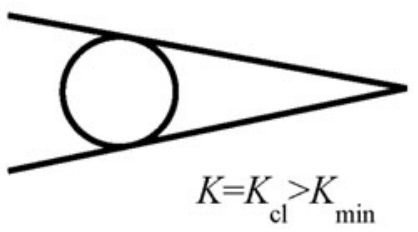

Crack closure

Figure 8: Schematic illustration of the influence of environment on the fatigue behavior of silicon thin films proposed by Kahn et al. Wear debris formed in dry air or vacuum accumulate in the crack wake, leading to crack closure. ${ }^{[36]}$

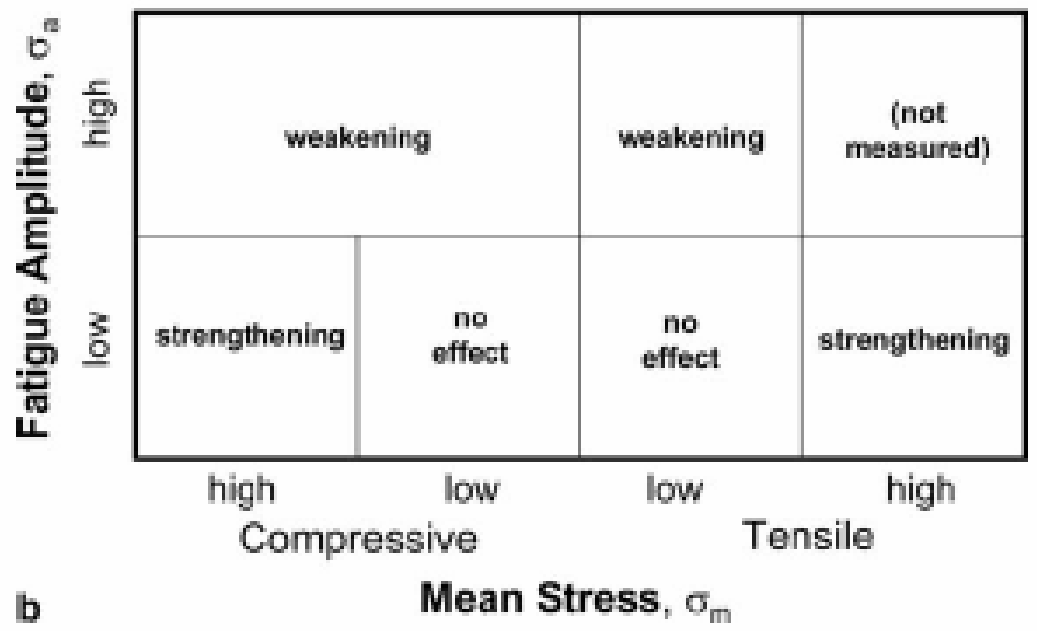

Figure 9: Qualitative weakening/strengthening map showing the influence of the fatigue amplitude and mean stress. ${ }^{[13]}$

Strengthening is found at low fatigue amplitude where the mean stress is highly compressive or highly tensile. No effect is found at low fatigue amplitudes with low mean stress (compressive or tensile). 
To account for these "weakening" and "strengthening" effects, Kahn et al. suggest three possible fatigue mechanisms. The first of these involves microcracking of the silicon; they argue that this would account for the weakening, and also for the strengthening due to cracktip shielding, although they admit that this explanation is "unappealing". A second mechanism was suggested involving dislocation activity, which would cause crack-tip blunting in the case of a strengthening effect and crack-tip blunting followed by sharpening for a weakening effect. They cite evidence for this mechanism that such dislocation motion has been reported for indentation experiments at room temperature, and that the loading conditions for small fatigue amplitudes and high compressive mean stresses would present similar shear stresses; however, observations of room temperature dislocation plasticity in silicon show a substantial residue of dislocations in the strained area after unloading - for a similar mechanism to be operative during fatigue there should be a readily detectable dislocation density observed in the silicon itself. This has not been found in the studies to date ${ }^{[11,13]}$. The reason for this high dislocation density is that at room temperature, dislocations to not move by thermally-activated kink motion, but rather by stress-assisted kink motion. Upon removal of the load, the dislocations are 'frozen' into the structure, and are thus readily observable. Additionally, there has been no direct evidence to date (e.g., from TEM imaging) where dislocations have been seen at arrested crack tips in silicon; roomtemperature dislocation plasticity in silicon has only been observed to date during the high combined compressive and shear loads of an indentation test ${ }^{[38]}$. Their third possible mechanism involved grain-boundary plasticity, where an amorphous grain-boundary region hitting the surface under stress would experience a non-conventional plastic deformation in shear, which would then cause a residual compressive stress, possibly resulting in the 
observed strengthening effect. Kahn et al. presented a finite-element model to show that with such grain-boundary plasticity residual compressive stresses could occur (independently of the fact of the applied mean stress is compressive or tensile). Varvani-Farahani ${ }^{[39]}$ suggested a related type of mechanism based on modeling of cyclic slip of silicon. However, theories based on cyclic slip in silicon have no physical basis below the ductile-to-brittle transition temperature ${ }^{[5]}$ and their claimed ability to "predict" a stress-life fatigue curve is based on an n-parameter curve fitting, which, we believe, should not be construed as an indication of mechanistic accuracy. No experimental evidence for both of these modeled results exists; furthermore, the fact that single-crystal micron-scale silicon is also susceptible to fatigue failure is totally inconsistent with any mechanism involving only grain boundaries. Most importantly, these mechanisms do not account for the fact that fatigue is not observed in macroscale silicon; moreover, purely mechanical mechanisms are inconsistent with the definitive effect of environment found in many thin-film silicon fatigue studies ${ }^{[19,20,21,30,31]}$.

Stress-life fatigue data were also reported by Kapels, Aigner and Binder ${ }^{[40]}$ on $4 \mu \mathrm{m}$ thick polysilicon. These authors used Weibull statistics to determine a mean fracture strength of their tensile specimens of $2.9 \pm 0.5 \mathrm{GPa}$, with a Weibull modulus of $6.4 \pm 1$. Additionally, their $S$ - $N$ fatigue data indicated delayed failure after cyclic loading, at $1 \mathrm{~Hz}$ at $R=0$, for maximum stresses below the mean fracture strength; fatigue lives were increased with decreasing maximum stress. Fatigue failure was observed after $10^{6}$ cycles for a maximum tensile stress of $2.2 \mathrm{GPa}$ (Figure 10). 


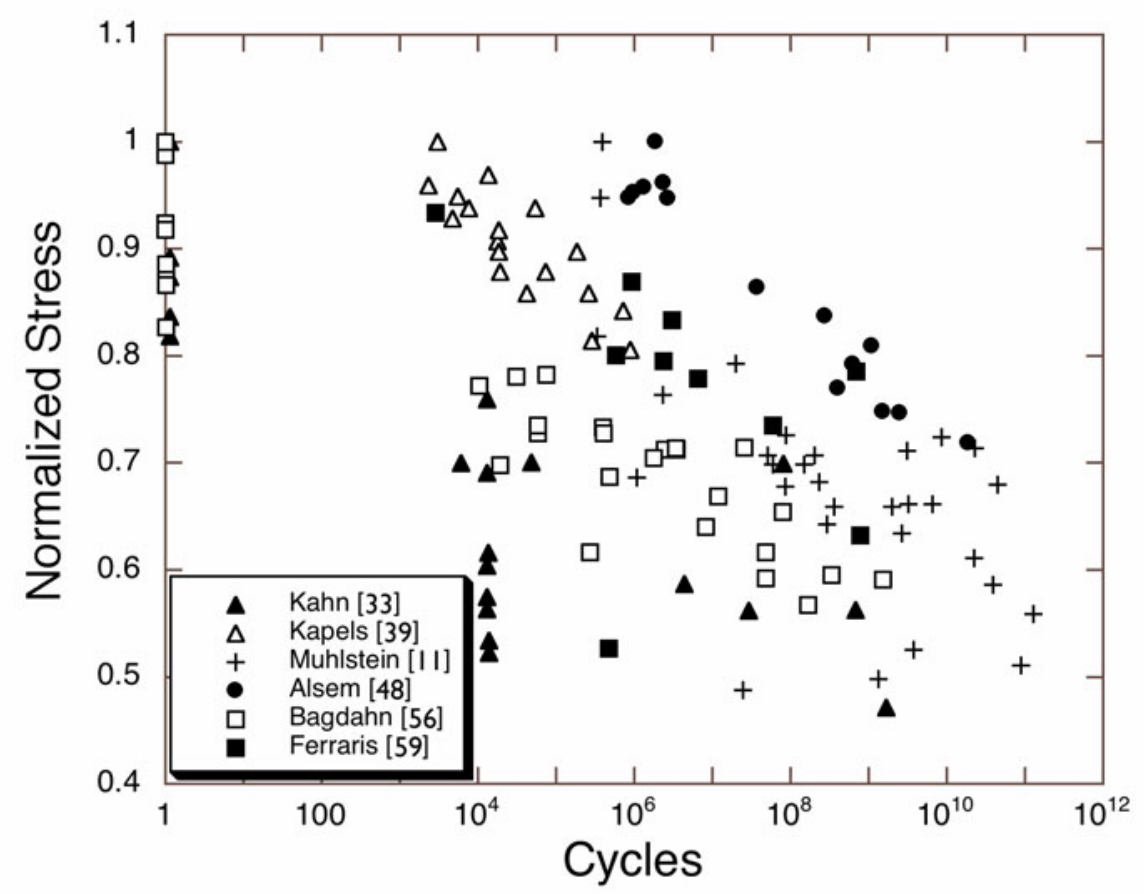

Figure 10: Combined, normalized, applied maximum stress vs. number of cycles to failure $(S-N)$ data for fatigue of polysilicon in ambient air. The stress values are normalized with respect to the stress from the test in that particular study that was run at the lowest number of cycles (and therefore in all but one case also with the test run at the highest stress).

More recently, Muhlstein et al. ${ }^{[1,41-43]}$ presented extensive stress-life fatigue results for 2 $\mu \mathrm{m}$ thick polysilicon films (fabricated at the MEMSCAP Multi User MEMS Process (MUMPs) Foundry ${ }^{[44,45]}$, where they observed an increase in fatigue life from $\sim 3 \times 10^{5}$ to $1.2 \times 10^{11}$ cycles by decreasing the sinusoidal stress amplitude from 4.0 to $2.0 \mathrm{GPa}$ (Figure 10); these tests were performed at $\sim 40 \mathrm{kHz}$ at $R=-1$, using a resonating cantilever-beam system similar to that shown in Figure 2. Fatigue failure was accompanied by a monotonic decrease in resonant frequency during cycling, which was interpreted as fatigue damage accumulation, specifically in terms of subcritical cracking and oxidation ${ }^{[46]}$. From these 
results, a detailed mechanism for thin film silicon fatigue was proposed by Muhlstein, Stach and Ritchie ${ }^{[11,42]}$ based on the notion of reaction-layer fatigue, which involves moistureinduced stable cracking in the thickened oxide layer. Evidence for this was found in highvoltage transmission electron microscopy (HVTEM) images of control specimens, fatigued specimens, and specimens interrupted prior to failure, which revealed striking differences in the surface oxide found at the notch $\operatorname{root}^{[11,42]}$. A native surface oxide of $\sim 30 \mathrm{~nm}$ in thickness was uniformly distributed over the surfaces of the control samples. In contrast, the surface oxide layer was significantly thicker (up to $90 \mathrm{~nm}$ ) at the notch root of fatigued specimens (Figure 11). In addition, HVTEM images of intact specimens that experienced a large number of cycles also revealed several stable small cracks within the thickened surface oxide, indicating the presence of subcritical crack growth (Figure 11). High-resolution infrared imaging of the fatigue specimen revealed only minimal temperature changes $(\sim 1 \mathrm{~K})$ during testing, which strongly implied that the enhanced notch root oxidation was not thermally induced but mechanical in origin ${ }^{[11]}$. As discussed below, since the cracking processes occurs within the oxide layer, this mechanism is consistent with the fact that bulk silicon is not susceptible to environmentally-induced cracking in air ${ }^{[9,16,28,34]}$. 

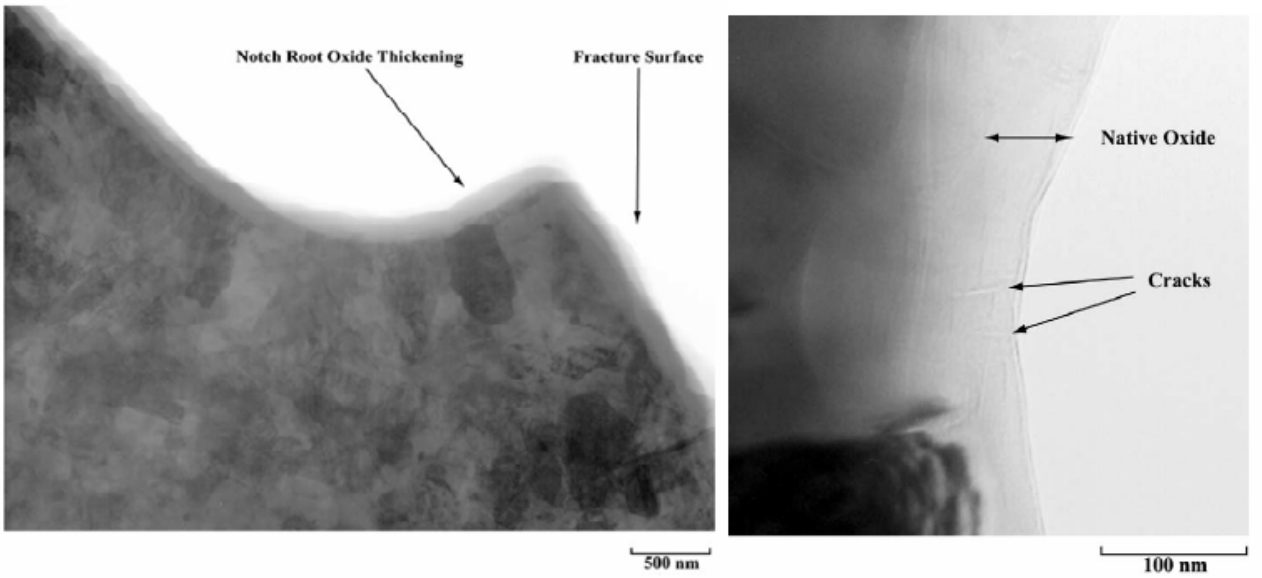

Figure 11: HVTEM images of the notch region in an unthinned, $2 \mu \mathrm{m}$ thick, polycrystalline silicon test sample after high-cycle fatigue. (left) This image shows enhanced oxidation at the notch root that failed, after $3.56 \times 10^{9}$ e cycles at stress amplitude of $\sigma_{a}=2.26 \mathrm{GPa}$. (Right) This image shows stable cracks, $\sim 50 \mathrm{~nm}$ in length, in the native oxide formed during cyclic fatigue loading; testing of this sample was interrupted after $3.56 \times 10^{9}$ cycles at a stress amplitude $\sigma_{a}=2.51 \mathrm{GPa}$. Image was intentionally defocused to facilitate the observation of the cracks. ${ }^{[11]}$

In light of these results, the fatigue of silicon thin films was attributed to a mechanism of sequential, cyclic stress-assisted oxidation and environmentally-assisted cracking of the surface oxide layer which forms upon exposure to moisture- and/or oxygen-containing atmospheres, a mechanism that they termed reaction-layer fatigue (Figure 12). The decrease in natural frequency of the fatigue characterization structure during testing, caused by a change of compliance of the resonator and measured using capacitive sensing, was found to be consistent with quantified damage evolution (using finite-element modeling) in the form of oxide thickening $(-0.5 \mathrm{~Hz}$ per nm of oxide growth) and subcritical crack growth $(-1 \mathrm{~Hz}$ per $\mathrm{nm}$ of crack extension) within the oxide (Figure 13) ${ }^{[11,41]}$. In particular, the maximum crack extension deduced from resonant frequency changes was found to be similar than the 
calculated critical crack size (through numerical modeling) and less than the observed surface oxide layer ${ }^{[43]}$. This implied that the entire process of fatigue crack initiation, growth and the onset of final failure of the entire structure occurred within the oxide layer. Since the crack in the oxide layer must cause failure of the entire structure, the criterion for this mechanism is that the thickness of the oxide layer, $h$, must be greater than or equal to the critical crack size, $a_{\mathrm{c}}$, to fail the entire structure, i.e., when $a_{\mathrm{c}}<h$. Because the oxide layer thickness in bulk silicon will only be a tiny fraction of the material, the beauty of this mechanism is that it provides an explanation as to why no delayed failure would occur by fatigue in bulk silicon as a growing crack in the oxide layer could never get large enough to break the entire structure i.e., as $a_{\mathrm{c}}>h$. Using a fracture-mechanics analysis, Mulhstein and Ritchie ${ }^{[43]}$ defined the range of oxide thicknesses where reaction-layer fatigue would be viable; their calculations suggested that a oxide thickness of $\sim 50 \mathrm{~nm}$ was required. Subsequent work by Pierron and Muhlstein ${ }^{[47]}$ expanded this numerical model to account for an alternative failure scenario where stable crack growth in the oxide changes to unstable crack growth when the crack hits the silicon/oxide interface, i.e., when $a_{\mathrm{c}}=h$; this lowered the oxide thickness that is potentially susceptible to reaction-layer fatigue to $\sim 15 \mathrm{~nm}$. The mechanism also explained the decreasing growth rates observed for cracks propagating within the oxide layer; as these cracks approach the $\mathrm{SiO}_{2} / \mathrm{Si}$ interface (with its three-fold modulus mismatch), fracturemechanics calculations of the crack-driving force showed that it decreased as cracks got closer to the interface ${ }^{[43]}$. 

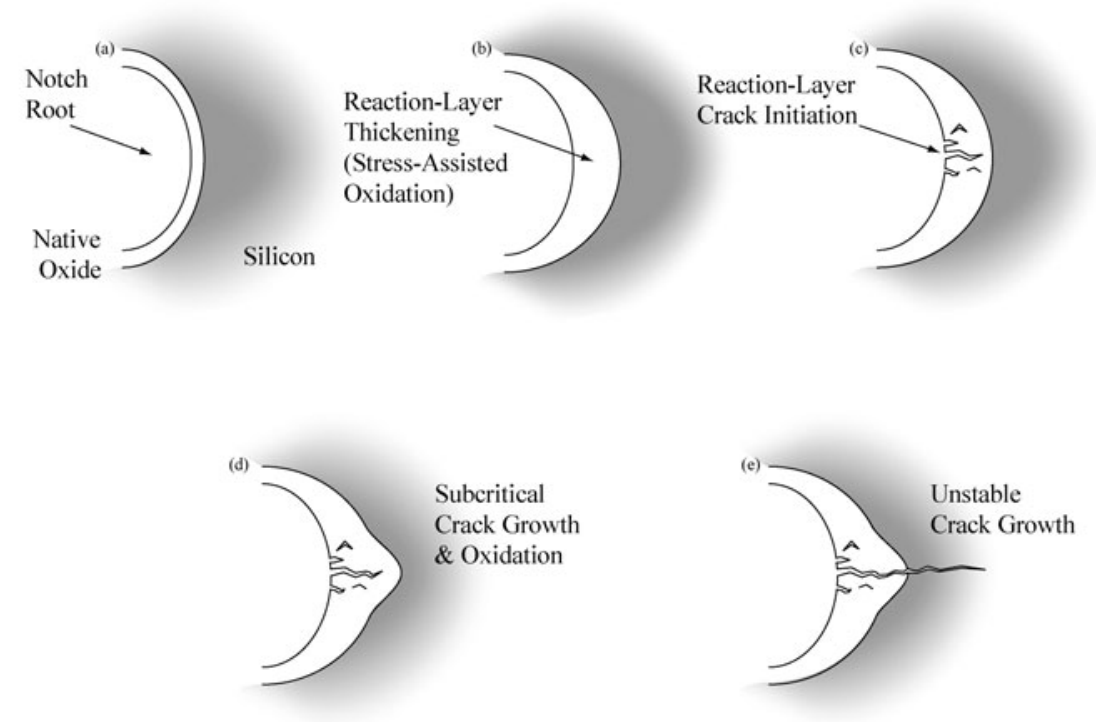

Figure 12: Schematic illustration of the reaction-layer fatigue mechanism for thin-film fatigue at the notch of the polycrystalline silicon cantilever beam: (a) reaction layer (postrelease oxide) on surface of the silicon, (b) localized cyclic stress-assisted oxide thickening at the notch root, (c) moisture-assisted crack initiation in the surface oxide at the notch root, (d) additional thickening and cracking of reaction-layer, and (e) unstable crack growth in the silicon film. ${ }^{[1]}$

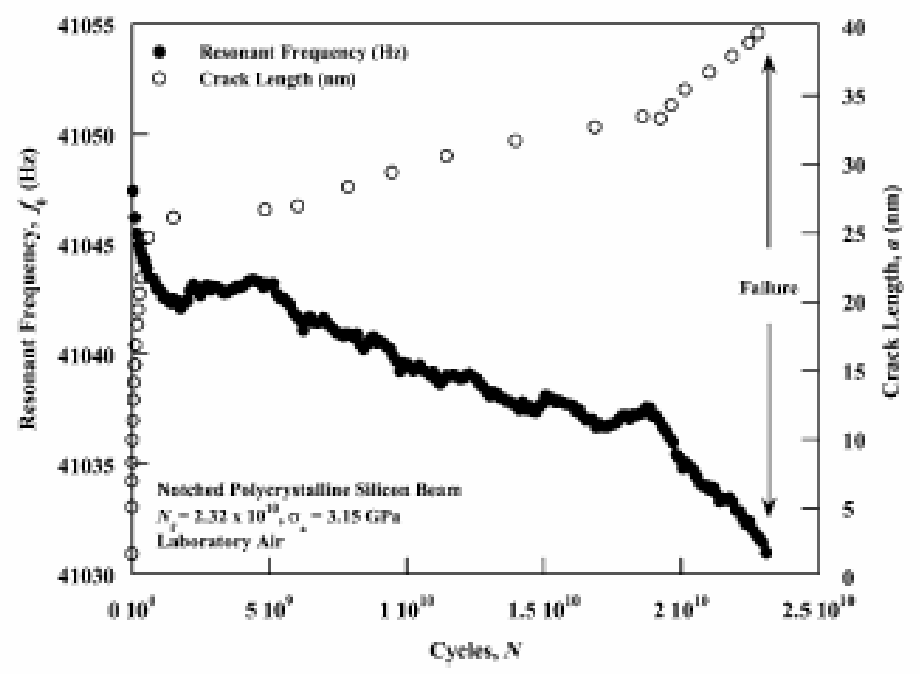

Figure 13: Representative damage accumulation in polycrystalline silicon, shown by experimentally measured decrease in resonant frequency, $f_{\text {crack }}$, with cycles during a fatigue test $\left(N_{\mathrm{f}}=2.23 \times 10^{10}\right.$ cycles at $\left.\sigma_{\mathrm{a}}=3.15 \mathrm{GPa}\right)$ and the corresponding computed increase in crack length, $a .^{[11]}$ 
Another recent study, by Alsem et al. ${ }^{[48,49]}$, confirmed, using HVTEM, the presence of this cyclic stress-assisted oxidation on resonator specimens similar to the ones used by Muhlstein et al. (i.e., MUMPs fabricated $2 \mu \mathrm{m}$ thick polysilicon ${ }^{[44,45]}$ ). Enhanced oxide thicknesses were imaged at the locations of maximum stresses after fatigue cycling, but not in samples that had been monotonically loaded and failed by overload fracture; such reaction layers were also not found after cycling in high vacuum $\left(2 \times 10^{-5} \mathrm{~Pa}\right)$ (Figure 14). Fatigue lives in ambient air $\left(25^{\circ} \mathrm{C}, 30-40 \% \mathrm{RH}\right)$ ranging from $8 \times 10^{5}$ to $2 \times 10^{10}$ cycles were measured for applied stresses ranging from 3.6 to $2.6 \mathrm{GPa}$ (Figure 10). Similar to the effects of coating silicon films with monolayer barrier coatings ${ }^{[11,42]}$, Alsem et al. found that the absence of oxygen and water vapor in a $2 \times 10^{-5} \mathrm{~Pa}$ vacuum environment completely suppressed the occurrence of delayed fatigue (consistent with the absence of a reaction layer); samples subjected to applied stresses up to $3.45 \mathrm{GPa}$ survived lifetimes of more than $10^{10}$ cycles without failure (Figure 15) ${ }^{[48]}$. They also showed that samples tested in high relative humidity $(>95 \% \mathrm{RH})$ air failed after fewer numbers of cycles than corresponding samples tested in ambient air $(\sim 35 \% \mathrm{RH})$; indeed, in the moist environment, failures were seen at $\sim 10^{9}$ cycles at applied stresses as low as $2.4 \mathrm{GPa}$ (Figure 15) ${ }^{[49]}$.

One puzzling aspect of the these studies was the thick post-release oxide layers found on the MUMPs ${ }^{[44,45]}$ fabricated fatigue samples studied by Muhlstein, Ritchie, Alsem and coworkers ${ }^{[11,41,42,48,49]}$; whereas native oxides on the order of a few nanometers thick are expected for polysilicon films, the initial oxides on the MUMPs samples were $20 \mathrm{~nm}$ or more. Pierron et al. ${ }^{[50]}$ examined this phenomenon and found that these relatively thick oxides can be formed at room temperature during "release", i.e., chemical removal of the silica layer in an HF bath, due to a galvanic effect between the n+-type silicon and gold (the polysilicon 
MUMPs process has a gold deposition step ${ }^{[45]}$ ). The growth of these surface oxides in concentrated HF solutions, that are usually associated with oxide dissolution, was predicted from the measured current-density/voltage behavior and the geometry of the galvanic couple, and verified by Auger electron spectroscopy measurements. This explanation for thickened post-release oxide layers in MUMPs processed MEMS was later confirmed by Kahn et al. ${ }^{[51]}$.

A complementary mechanism to reaction-layer fatigue was proposed by Allameh, Soboyejo, and coworkers ${ }^{[12,52-54]}$, who studied the evolution of surface morphology of polysilicon MEMS during cyclic actuation, using the same fatigue resonators as Muhlstein et al. (Figure 2). In situ AFM images of the region near the notch, before and after cyclic actuation at a stress amplitude of $2.7 \mathrm{GPa}$ for $2 \times 10^{9}$ cycles, revealed definitive changes in surface topology (Figure 16). Specifically, the measured roughness of the surface in the immediate vicinity of the notch was found to increase after cycling from 10 to $20 \mathrm{~nm}$. The roughness changes diminished with increasing distance from the notch, indicating a role of stress in the evolution of surface topography under cyclic loading. Although no measurements of the oxides were made, these surface topology changes were ascribed to the roughening of the surface oxide layer; this in turn was associated with a mechanism of cyclic stress-assisted dissolution of the oxide layer that could result in fatigue crack nucleation through the evolution of surface grooves. 

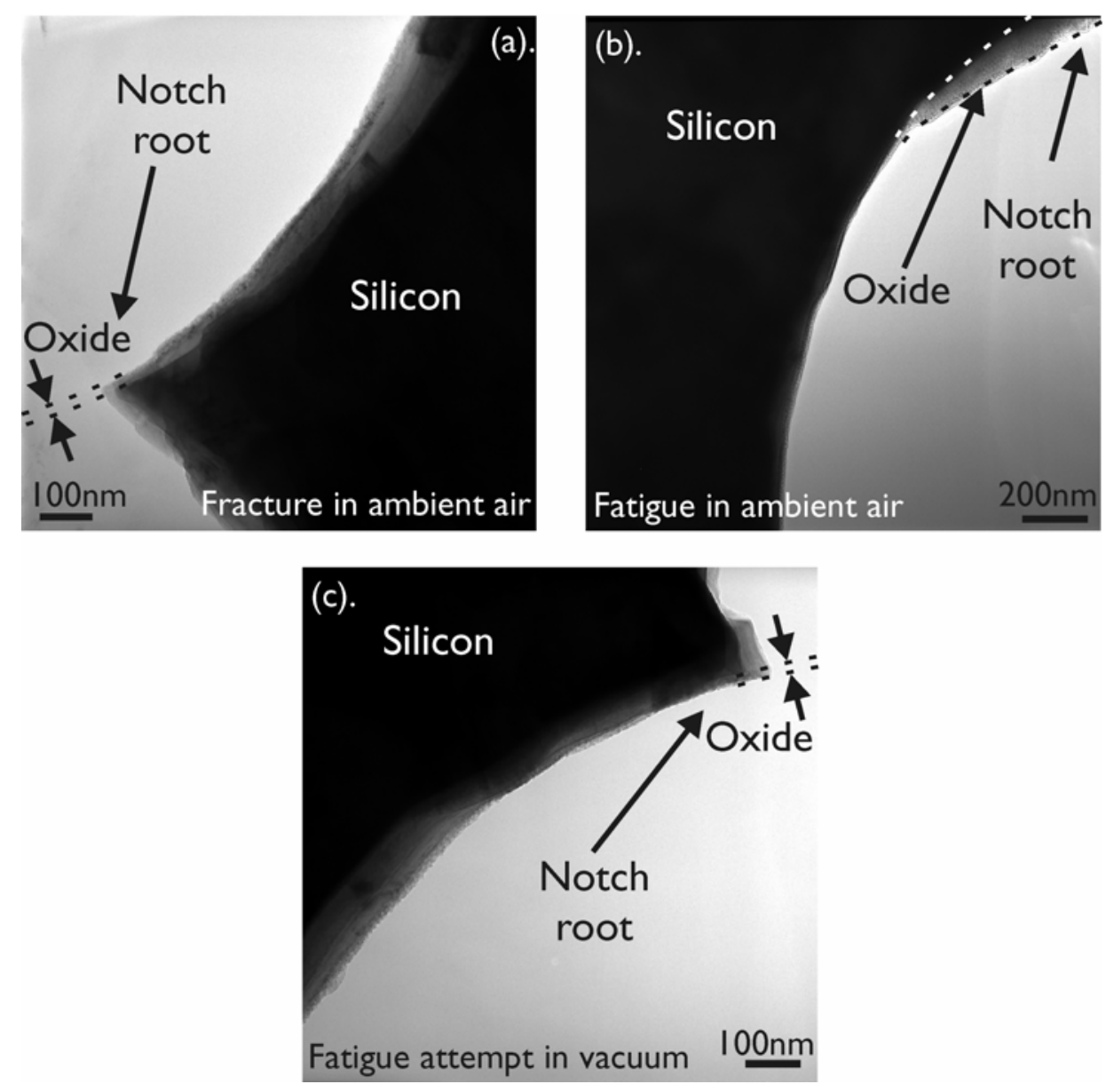

Figure 14: HVTEM images from failed MUMPs resonator devices. (a) Monotonically fractured specimen in ambient air: no (local) oxide thickening. Because of sample tilt, some contrast in grains at the edge is visible. Only the top transparent part is amorphous; (b) fatigued in ambient air with thickened oxide layer at the notch root (maximum cyclic stress at the notch root: $2.86 \mathrm{GPa}$; number of cycles at failure: $6.28 \times 10^{8}$ ); (c) device after fatigue attempt in vacuo and subsequent single-cycle fracture: no oxide layer thickening (maximum cyclic stress at the notch root during fatigue attempt: $3.29 \mathrm{GPa}$, number of cycles when stopped: $1.14 \times 10^{10}$ ). Also in this case contrast from grains on the edge is visible; only the top amorphous layer is oxide. ${ }^{[48]}$ 


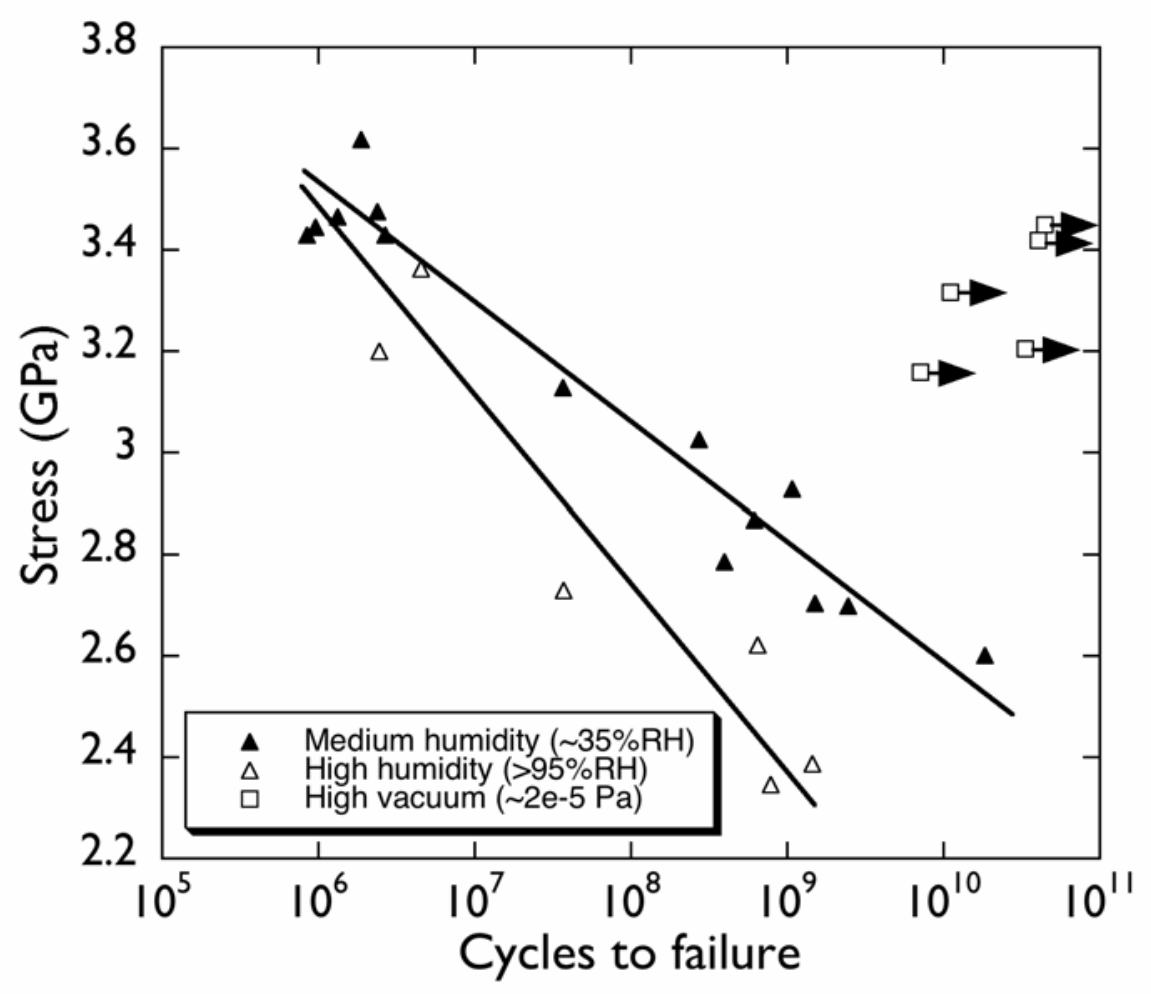

Figure 15: $S-N$ fatigue data showing polysilicon fatigue resonator devices run in ambient air $\left(\sim 25^{\circ} \mathrm{C}, \sim 35 \% \mathrm{RH}\right)$ in general have longer lives than corresponding devices run at high relative humidity $(>95 \% \mathrm{RH})$. No fatigue failures were found in vacuo $\left(2 \times 10^{-5} \mathrm{~Pa}\right)$; the vacuum data points are run-outs. ${ }^{[49]}$ 

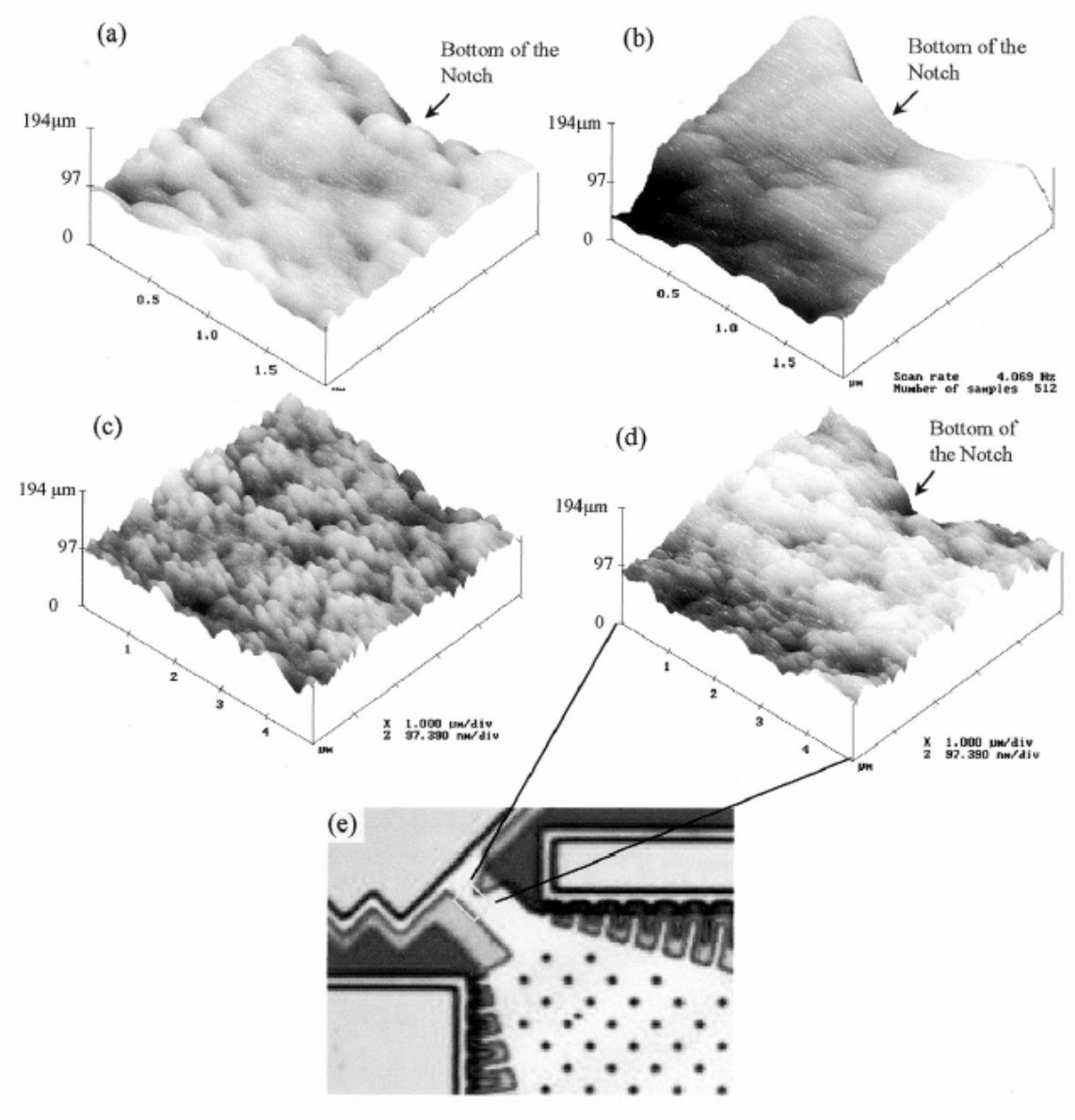

Figure 16: Surface topography evolution showing in a series of AFM surface scans of the area below the notch tip: (a) Before actuation, (b) After the actuation of polysilicon structures for $2 \times 10^{9}$ cycles on a $2 \mu \mathrm{m} \times 2 \mu \mathrm{m}$ scale; (c) and (d) are corresponding images on a $5 \times 5 \mu \mathrm{m}$ scale (before and after actuation, respectively), (e) Location of scan area at the vicinity of the notch root of the fatigue resonator (similar design as shown in Figure 2) corresponding to (a)-(d). ${ }^{[12]}$

The specific influence of frequency on the high-cycle fatigue behavior of thin-film polysilicon (3.5 $\mu \mathrm{m}$ thick, 1.1 GPa tensile strength) was investigated by Bagdahn and Sharpe [55-57], who derived $S-N$ fatigue curves using tensile specimens (Figure 17) cycled at 50, 200, 1000 and $6000 \mathrm{~Hz}$. Results showed similar trends at all frequencies (Figure 18); the fatigue 
life increased with decreasing maximum tensile stress, with specimens failing after $10^{9}$ cycles at a peak stress of $0.7 \mathrm{GPa}$, some $35 \%$ lower than the tensile strength of the material (Figure 10). SEM images revealed probable failure initiation from the sidewalls, which was assumed to be caused by a defect generated under cyclic loading. AFM measurements of the surface roughness revealed that the surface near the fracture site was significantly rougher $(17.2 \mathrm{~nm})$ than the surface of a specimen not subjected to high cyclic stresses $(\sim 8 \mathrm{~nm})$. The authors concluded that cracking induced by the environment only could not be the mechanism responsible for the fatigue behavior of silicon thin films, as a purely environmentally-assisted cracking mechanism would lead to a constant failure time, independent of the frequency ${ }^{[58]}$. Instead, their results suggested that the number of loading cycles to failure was independent of frequency, i.e., the time to failure decreased with increasing frequency. They concluded that most likely, an additional effect (other than the environmental influences) was present to account for these results.

Finally, additional $S / N$ data on $15 \mu \mathrm{m}$ thick polysilicon were recently published by Ferraris et al. ${ }^{[59]}$, who used a comb-driven reciprocal rotor actuator, similar to the design used by White et al. ${ }^{[60]}$, which causes a fully reversed bending load in an unnotched beam. They presented an $S / N$ fatigue curve where the stress is given on a relative scale, based on capacitive displacement measurements (Figure 10). They observe delayed failure after $\sim 10^{9}$ cycles for applied stresses of a $\sim 70 \%$ of the single cycle fracture stress. No failure was found for devices run for more than $10^{9}$ cycles at stresses varying from 50 to $80 \%$ of the single cycle fracture stress. No mechanistic explanations were presented. 


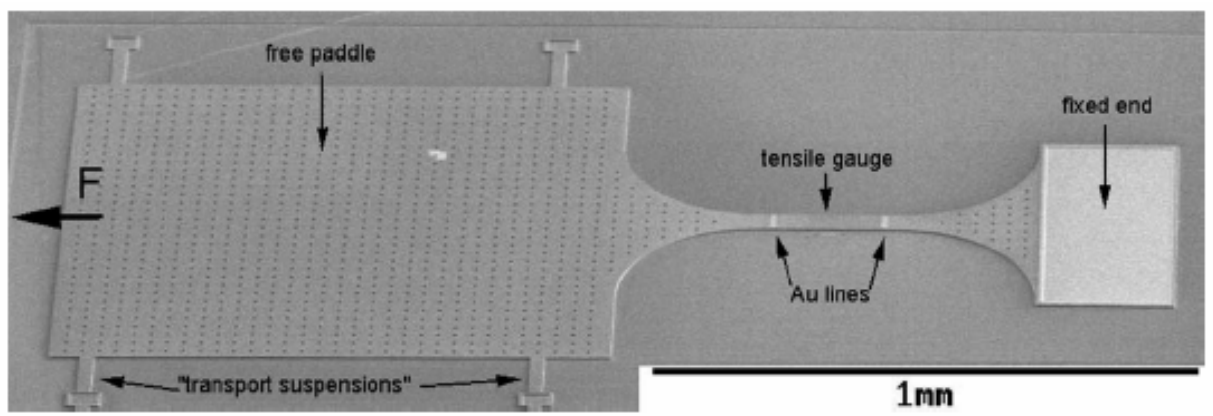

Figure 17: Scanning electron microscope image of the miniature tensile specimen used in the study of Bagdahn and Sharpe ${ }^{[55-57]}$. The free paddle is attached to an external loading system during the fatigue test.

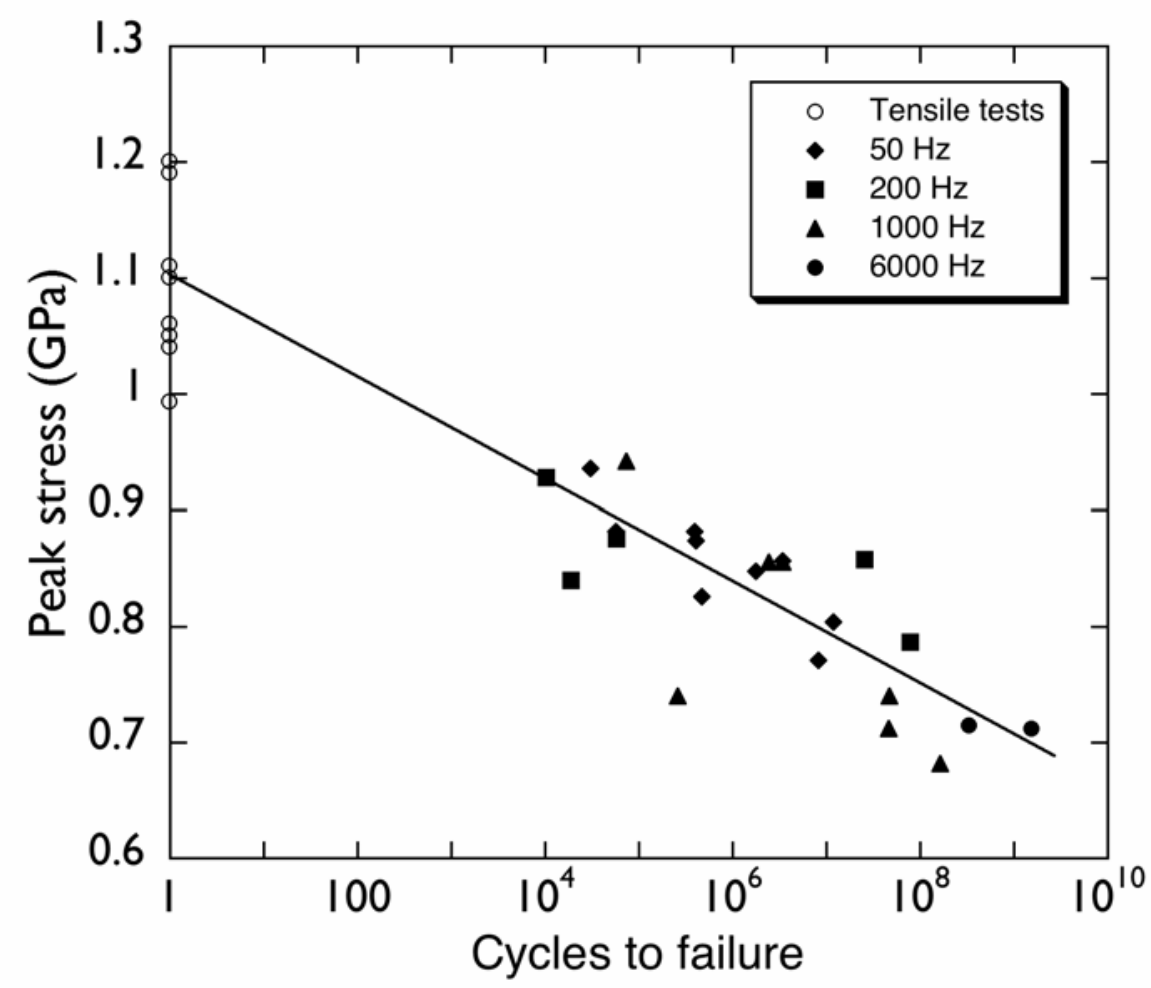

Figure 18: Stress-lifetime $(S / N)$ curve of thin-film polysilicon tensile specimens during cyclic loading tested with different loading frequencies between 50 and $6,000 \mathrm{~Hz} .^{[56]}$ 
Table 2: Summary of fatigue testing of polycrystalline silicon thin films from 1999 to 2006. The upwards and downwards pointing arrow-symbols refer respectively to increases and decreases.

\begin{tabular}{|c|c|c|c|c|}
\hline Authors & $\begin{array}{l}\text { Specimen } \\
\text { Geometry }\end{array}$ & $\begin{array}{l}\text { Actuation Mode / Output } \\
\text { Signal Measurement }\end{array}$ & $\begin{array}{c}\text { Frequency } \\
f \text {, Stress } \\
\text { Ratio } R\end{array}$ & Results \\
\hline $\begin{array}{l}\text { Van Arsdell, } \\
\text { Brown } \\
{[32]}\end{array}$ & $\begin{array}{l}\text { Precracked cantilever } \\
\text { beam }(20 \mu \mathrm{m} \text { wide, } \\
40 \mu \mathrm{m} \text { long, } 2 \mu \mathrm{m} \\
\text { thick) attached to } \\
\text { large plate. }\end{array}$ & $\begin{array}{l}\text { Electrostatic actuation at } \\
\text { resonance (in-plane motion). } \\
\text { Capacitive sensing of motion. }\end{array}$ & $\begin{array}{c}45-48 \mathrm{kHz} \\
R=-1\end{array}$ & $\begin{array}{l}f_{0} \downarrow \text { during lifetime (wet air, } K_{a p p}= \\
0.3 \mathrm{MPa} \cdot \mathrm{m}^{1 / 2} \text { ). } \\
f_{0} \text { constant in dry air. } \\
f_{0} \text { constant with uncracked } \\
\text { cantilever beam. } \\
\text { Transgranular crack path. }\end{array}$ \\
\hline $\begin{array}{l}\text { Kahn, Ballarini, } \\
\text { Heuer, et al. } \\
{[13,33-35]}\end{array}$ & $\begin{array}{l}\text { Fracture-mechanics } \\
\text { specimen } \\
\text { (precracked, } 60 \mu \mathrm{m} \\
\text { wide, } 500 \mu \mathrm{m} \text { long, } \\
\sim 3 \mu \mathrm{m} \text { thick). } \\
\text { Notched cantilever } \\
\text { beam }(1 \mu \mathrm{m} \text { radiused } \\
\text { notch, } 5.2 \mu \mathrm{m} \text { thick) }\end{array}$ & $\begin{array}{l}\text { Electrostatic actuation at } \\
\text { resonance with superposition } \\
\text { of DC voltage (in-plane } \\
\text { motion). } \\
\text { Displacement visually } \\
\text { recorded. }\end{array}$ & $\begin{array}{c}20 \mathrm{kHz} \\
-3<R<0.5\end{array}$ & $\begin{array}{l}\text { Failure after } 10^{9} \text { cycles for } \sigma_{\max }= \\
50 \% \sigma_{\mathrm{f}} \text {. } \\
\text { No high-cycle fatigue failure in } \\
\text { vacuum }(8 \mathrm{~Pa}) \text {. } \\
\text { No stress-corrosion cracking } \\
\text { observed. } \\
\text { Fatigue strength } \downarrow \text { as } R \downarrow \text { and } \uparrow \text { as } \\
\mathrm{R} \uparrow\end{array}$ \\
\hline $\begin{array}{l}\text { Kapels, Aigner, } \\
\text { Binder, et al. } \\
{[40]}\end{array}$ & $\begin{array}{l}\text { Beam }(0.7 \mu \mathrm{m} \text { wide, } \\
5 \mu \mathrm{m} \text { long, } 4 \mu \mathrm{m} \\
\text { thick })\end{array}$ & $\begin{array}{l}\text { Thermal actuation (load up to } \\
10 \mathrm{mN} \text { ). } \\
\text { Displacements measured } \\
\text { optically. }\end{array}$ & $\begin{array}{l}1 \mathrm{~Hz} \\
R=0\end{array}$ & $\begin{array}{l}\text { Mean fracture strength: } 2.9 \pm 0.5 \\
\text { GPa } \\
\text { Fatigue lives } \uparrow \text { as } \sigma_{\max } \downarrow, N_{\mathrm{f}}=10^{6} \\
\text { cycles for } \sigma_{\max }=2.2 \mathrm{GPa}\end{array}$ \\
\hline $\begin{array}{l}\text { Muhlstein, } \\
\text { Ritchie, et al. } \\
{[11,41-43]}\end{array}$ & $\begin{array}{l}\text { Notched cantilever } \\
\text { beam }(20 \mu \mathrm{m} \text { wide, } \\
40 \mu \mathrm{m} \text { long, } 2 \mu \mathrm{m} \\
\text { thick) attached to } \\
\text { large plate. }\end{array}$ & $\begin{array}{l}\text { Electrostatic actuation at } \\
\text { resonance (in-plane motion). } \\
\text { Capacitive sensing of motion. } \\
\text { Visual calibration. } \\
\text { HVTEM imaging of silicon- } \\
\text { oxide. }\end{array}$ & $\begin{array}{c}\sim 40 \mathrm{kHz} \\
R=-1\end{array}$ & $\begin{array}{l}\text { Fatigue lives in lab. air } \uparrow \text { from } 3 \times \\
10^{5} \text { to } 10^{11} \text { cycles by } \downarrow \sigma_{\mathrm{a}} \text { from } 4 \text { to } \\
2 \mathrm{GPa} \text {. } \\
f_{0} \downarrow \text { during lifetime (as large as } 50 \\
\mathrm{~Hz} \text { ). } \\
\text { Transgranular crack path. } \\
\text { HVTEM revealed oxide thickening } \\
\text { at the notch root after cyclic } \\
\text { actuation, along w/ stable cracks } \\
\text { within thickened surface oxide. } \\
\text { No delayed failure in ultra high } \\
\text { vacuum. }\end{array}$ \\
\hline $\begin{array}{l}\text { Alsem, Stach, } \\
\text { Ritchie, et al. } \\
{[48,49]}\end{array}$ & $\begin{array}{l}\text { Notched cantilever } \\
\text { beam }(20 \mu \mathrm{m} \text { wide, } \\
40 \mu \mathrm{m} \text { long, } 2 \mu \mathrm{m} \\
\text { thick) attached to } \\
\text { large plate. }\end{array}$ & $\begin{array}{l}\text { Electrostatic actuation at } \\
\text { resonance (in-plane motion). } \\
\text { Capacitive sensing of motion. } \\
\text { Visual calibration. } \\
\text { HVTEM imaging of silicon- } \\
\text { oxide. }\end{array}$ & $\begin{array}{c}\sim 40 \mathrm{kHz} \\
R=-1\end{array}$ & $\begin{array}{l}\text { Fatigue lives in lab air } \uparrow \text { from } 8 \times \\
10^{5} \text { to } 2 \times 10^{10} \text { cycles by } \downarrow \sigma_{\mathrm{a}} \text { from } \\
3.6 \text { to } 2.6 \mathrm{GPa} \text {. } \\
\text { No failure in very high vacuum } \\
\text { Fatigue lives } \downarrow \text { with high RH } \\
\text { HVTEM revealed oxide thickening } \\
\text { at the notch root after fatigue in air, } \\
\text { but not on single-cycle fracture and } \\
\text { after fatigue attempts in vacuum. }\end{array}$ \\
\hline $\begin{array}{l}\text { Allmeh, } \\
\text { Brown, } \\
\text { Sobejeyo, et al. } \\
{[12,52-54]}\end{array}$ & $\begin{array}{l}\text { Notched cantilever } \\
\text { beam }(20 \mu \mathrm{m} \text { wide, } \\
40 \mu \mathrm{m} \text { long, } 2 \mu \mathrm{m} \\
\text { thick) attached to } \\
\text { large plate. }\end{array}$ & $\begin{array}{l}\text { Electrostatic actuation at } \\
\text { resonance (in-plane motion). } \\
\text { Capacitive sensing of motion. } \\
\text { Visual calibration. } \\
\text { In situ AFM techniques }\end{array}$ & $\begin{array}{c}\sim 40 \mathrm{kHz} \\
R=-1\end{array}$ & $\begin{array}{l}\text { AFM revealed rougher surfaces } \\
\text { near the notch area after cycling. }\end{array}$ \\
\hline $\begin{array}{l}\text { Bagdahn, } \\
\text { Sharpe } \\
{[55-57]}\end{array}$ & $\begin{array}{l}\text { Tensile specimens } \\
(3.5 \mu \mathrm{m} \text { thick })\end{array}$ & $\begin{array}{l}\text { External actuation } \\
\text { (piezoelectric actuator, load } \\
\text { speaker) } \\
\text { Load cell measurements. } \\
\text { AFM roughness measurement }\end{array}$ & $\begin{array}{c}50,200 \\
1000,6000 \\
\mathrm{~Hz} \\
R=0\end{array}$ & $\begin{array}{l}\text { Failure after } 10^{9} \text { cycles for } \sigma_{\max }= \\
65 \% \sigma_{\mathrm{f}} \text {. } \\
\text { AFM revealed rougher surface near } \\
\text { fatigued region. } \\
N_{\mathrm{f}} \text { independent of frequency. }\end{array}$ \\
\hline $\begin{array}{l}\text { Ferraris, Fasso, } \\
\text { Del Sarto, et al. } \\
\text { [59] }\end{array}$ & $\begin{array}{l}\text { Comb-driven } \\
\text { reciprocal rotor }(1.8- \\
4.4 \mu \mathrm{m} \text { wide, } 34 \mu \mathrm{m} \\
\text { long, } 15 \mu \mathrm{m} \text { thick). }\end{array}$ & $\begin{array}{l}\text { Electrostatic actuation. } \\
\text { Capacitive sensing of motion. }\end{array}$ & $\begin{array}{l}4 \mathrm{kHz} \\
R=-1\end{array}$ & $\begin{array}{l}\text { Failure after up to } 10^{9} \text { cycles at } \\
70 \% \text { of fracture strength. } \\
\text { No failure after }>10^{9} \text { cycles at } 50- \\
80 \% \text { of fracture strength. }\end{array}$ \\
\hline
\end{tabular}




\section{Discussion}

The results presented above clearly establish the phenomenon of the susceptibility of micron-scale single and polycrystalline silicon films to fatigue failure in ambient air under cyclic loading; this is in contrast to bulk silicon which shows no such susceptibility to cyclic fatigue. Based on a wide spectrum of studies (listed in Tables 1 and 2) involving a range of different testing methods (described in the Appendix), stress-lifetime data (Figures 1,10) for thin-film silicon show relatively consistent trends, specifically that stress amplitudes as low as half the (single-cycle) fracture stress can cause delayed fatigue failure, typically after $10^{11}$ cycles or more ${ }^{[11,24,31,33,48]}$. Such fatigue failure has been reported for various modes of cyclic loading, specifically for fully reversed cyclic loading $(R=-1)^{[4,11-15,18,19,24,30-35,41-43,48,49,52-54,59]}$ and tensile loading with a positive mean stress $(R \geq 0)^{[13,21-23,25-29,33-35,40,55-57]}$. More importantly, the frequency of loading does not appear to influence the fatigue life ${ }^{[26,27,55-}$ 57]. These results suggest that the mechanism(s) responsible for such thin-film silicon fatigue must include both time-independent and cycle-dependent contributions, and that the phenomenon is unlikely to be the sole result of environmentally-induced cracking ${ }^{[28,29,34]}$, as this would lead to lifetimes in terms of time (and not in terms of cycles) which are frequencyindependent ${ }^{[58]}$.

In terms of physical understanding, two classes of mechanisms have been proposed to explain the fatigue degradation of silicon films. As noted above, the first of these associates the fatigue degradation process with a surface phenomenon. The most prominent mechanism of this type is the reaction-layer fatigue mechanism (Figure 12) ${ }^{[1,42,48]}$, which attributes thinfilm silicon fatigue to a process of sequential, cyclic stress-induced oxidation and moistureassisted cracking of the surface silicon-oxide layer. In this mechanism, subcritical crack growth occurs solely in the amorphous silicon oxide layer, and is associated with the well- 
known processes whereby the hydroxyl ions in water react chemically with the $\mathrm{SiO}_{2}$ at the crack tip to destroy the polar siloxane bonds and replace them with weaker hydrogen bonds ${ }^{\text {[61] }}$ Such environmentally-assisted cracking in the oxide leads to failure of the entire structure when the critical crack size is exceeded. The second class of mechanisms asserts that the damage processes evolve from purely mechanical subcritical cracking in the silicon itself ${ }^{[13]}$.

On the basis of the evidence presented in the studies reviewed, the reaction-layer mechanism appears to account for most experimentally observed effects. First and foremost, the absence of thin-film silicon fatigue failures in high vacuum, and the observed influence of humidity on the fatigue life are strong indications of a significant environmental contribution to cracking (Figure 5) ${ }^{[19,20,30,31,48,49]}$. However, observations that the number of cycles to failure is frequency-independent are clear indications of a true fatigue contribution too (Figure 18) ${ }^{[26,27,55]}$. Indeed, cyclic effects associated with moisture-assisted cracking of the silica layer are very plausible. Although it is a common belief that cyclic loading does not accelerate crack-growth rates in silicon-oxide structures ${ }^{[58]}$, cyclic fatigue has been reported for a borosilicate glass at very low growth rates $\left(<3 \times 10^{-8} \mathrm{~m} / \mathrm{s}\right)^{[62]}$. In addition, stress-life fatigue curves generated for nano-scale $\mathrm{SiO}_{2}$ beams did not exhibit a dependence on frequency ${ }^{[26,63]}$, again suggesting pure cyclic effects. Second, as noted above, the fact that macroscale silicon does not display fatigue susceptibility is consistent with the lack of influence of cracks in the silica layer at these larger scales. In macroscale structures, critical crack sizes to cause unstable fracture cannot be reached by cracks inside the oxide layer (which naturally does not scale with the size of the structure). Finally, the weakening effect, induced at compressive mean stresses and high fatigue amplitudes, as well as at low tensile mean stress and high fatigue stress (Figure 9) ${ }^{[13]}$ can also be explained. All these test 
conditions introduce fatigue damage by cyclic loading, lowering the apparent strengths. However, the reported strengthening at low stress amplitudes, where the mean stress is highly compressive or highly tensile ${ }^{[13]}$, cannot be explained by any mechanism at present and remains somewhat of a mystery.

The precise origin of the cyclic stress-assisted oxidation of silicon, which plays an important role in the reaction-layer fatigue mechanism, is not known. However, it is likely related to some form of stress-assisted diffusion or an increased oxidation reaction rate at the silicon/oxide interface. Compressive stresses occur in the silicon-oxide layer during oxidization because the molar volume of $\mathrm{SiO}_{2}\left(27 \mathrm{~cm}^{3} / \mathrm{mol}\right)$ is larger than for $\mathrm{Si}\left(12 \mathrm{~cm}^{3} / \mathrm{mol}\right)$. The decrease in oxidation rate as the silicon-oxide layer grows has been partly attributed to the presence of these stresses, because of a decrease in oxidant diffusion rate ${ }^{\text {[64-66]. }}$. Additionally, tensile stresses in the silicon generated by the oxide can cause the oxidation reaction at the silicon/oxide interface to occur more quickly ${ }^{[67]}$. When applying a cyclic load, the compressive stresses in the silicon oxide will be relieved during the tensile part of the loading cycle, which results in a smaller decrease in the oxidation reaction rate as the oxide grows thicker. Moreover, in combination with an applied compressive load in another part of the loading cycle, which increases the oxidation reaction, a rapid oxidation process could occur that results into the growth of a thicker oxide. This oxide thickening effect has been observed in all the fatigue studies where oxide thicknesses have been measured (Figure 11 and $14^{[11,48]}$, and is one clear characteristic of micron-scale silicon fatigue. With the direct observations of subcritical cracks in these oxide layers (Figure 11) ${ }^{[11,42]}$, which is shown to be consistent with the coupling of damage accumulation and decrease in resonance frequency of fatigue specimens (Figure 13) ${ }^{[11]}$, as well as surface roughening at points of high stress 
(Figure 16) ${ }^{[12,56]}$ as a result of the oxidation process, there is a compelling list of experimental evidence to support the reaction-layer mechanism. In contrast, this experimental evidence is lacking for mechanisms based on subcritical cracking of the silicon itself, as was shown in section 3.

Since silicon is neither prone to environmentally-assisted cracking nor fatigue failure in bulk form, these latter mechanisms of thin-film silicon fatigue involving subcritical cracking in the silicon itself are in essence totally inconsistent with the vast majority of experimental evidence. We strongly believe that mechanisms based on subcritical cracking in the oxide layer provide the only realistic explanation for the fatigue of silicon at the micron-scale.

\section{Summary and conclusions}

Silicon is widely used in microelectromechanical systems applications. However, because of its brittle nature, it is clearly not an ideal structural material. Although bulk silicon is not susceptible to fatigue, micron-scale silicon has been demonstrated to display delayed failures under cyclic fatigue loading at applied cyclic stresses as low as half the (single-cycle) fracture strength. Since the early 1990s, several mechanisms to explain such fatigue failures in micron-scale silicon (both single and polycrystalline) have been suggested. These mechanisms can be divided into two main classes, namely those which attribute fatigue to a surface effect caused by cracking in the silicon-oxide layer (e.g., reaction-layer fatigue) and those which propose that subcritical cracking in the silicon itself is the cause of thin-film silicon fatigue.

Based on a review of the extensive literature on this topic, it is apparent that in general the stress-lifetime $(S / N)$ fatigue data that have been measured by numerous authors all display 
similar trends, wherein lower cyclic stresses lead to a larger number of cycles to failure. Lifetimes are found to dependent markedly on the environment (e.g., no fatigue failures are found in high vacuum), yet to be largely independent of loading frequency when considered in terms of cycles (and not time) to failure. We argue that the published data from fatigue studies in both single and poly crystalline silicon present no convincing evidence to support the notion that the salient fatigue mechanisms involve subcritical cracking in the silicon itself. On the contrary, we find that the vast majority of experimental evidence on micron-scale, thin-film silicon fatigue is consistent with the concept of reaction-layer fatigue, where delayed failures result from cyclic stress-induced oxidation and consequent moisture-induced subcritical cracking in the silicon-oxide surface layer.

\section{Acknowledgements}

This work was supported by the Director, Office of Science, Office of Basic Energy Sciences, Division of Materials Sciences and Engineering, of the U.S. Department of Energy under Contract no. DE-AC02-05CH11231. The authors would like to thank the staff and the use of equipment at the National Center for Electron Microscopy, Lawrence Berkeley National Laboratory, which is supported by the Department of Energy under this contract. The generous support of The Pennsylvania State University (for O.N.P., and C.L.M.) is also acknowledged.

\section{References}

1. A.D. Romig Jr., M.T. Dugger and P.J. McWhorter, Acta Mat. 2003, 51, 5837.

2. R. Maboudian, W.R. Ashurst and C. Carraro, Tribology Letters 2002, 12, 95. 
3. K. Komvopoulos, Wear 1996, 200, 305.

4. J.A. Connally and S.B. Brown, Science 1992, 256, 1537.

5. K. Sumino, Metall. Mater. Trans. A 1999, 30A, 1465.

6. H. Kahn, N. Tayebi, R. Ballerini, R.L. Mullen and A.H. Heuer, Sens. Actuators A 2000, A82, 274.

7. T.J. Chen and W.J. Knap, J. Am. Ceram. Soc. 1980, 63, 225.

8. B.R. Lawn, D.B. Marshall and P. Chantikul, J. Mater. Sci. 1981, 16, 1769.

9. B. Wong and R.J. Holbrook, Journal of the Electrochemical Society 1987, 134, 2254.

10. R. O. Ritchie, Int. J. Fract. 1999, 100, 55.

11. C.L. Muhlstein, E.A. Stach and R.O. Ritchie, Acta Materialia 2002, 50, 3579.

12. S. Allameh, P. Shrotriya, A. Butterwick, S. Brown and W.O. Soboyejo, Journal of Microelectromechanical Systems 2003, 12, 313.

13. H. Kahn, L. Chen, R. Ballerini and A.H. Heuer, Acta Materialia 2006, 54, 667.

14. J.A. Connally and S.B. Brown, in International Conference on Solid-State Sensors and Actuators, Jun 24-28 1991, Publ. by IEEE, Piscataway, NJ, USA, 1991.

15. J.A. Connally and S.B. Brown, Experimental Mechanics 1993, 33, 81.

16. M.D. Thouless and R.F. Cook, Applied Physics Letters 1990, 56, 1962.

17. T.A. Michalske and S.W. Freiman, Journal of the American Ceramic Society 1983, 66, 284.

18. M. Tabib-Azar, K. Wong and W. Ko, Sensors and Actuators A 1992, 33, 199.

19. T. Tsuchiya, A. Inoue, J. Sakata, M. Hashimoto, A. Yokoyama and M. Sugimoto, 16th Sensor Symposium 1998, 277.

20. T. Tsuchiya, Fatigue Fract. Engng. Mater. Struct. 2005, 28, 665. 
21. K. Komai, K. Minoshima and S. Inoue, Micros. Tech. 1998, 5, 30.

22. K. Minoshima, T. Terada and K. Komai, Fatigue \& Fracture of Engineering Materials \& Structures 2000, 23, 1033.

23. T. Ando, M. Shikida and K. Sato, Sensors and Actuators A 2001, A93, 70.

24. C.L. Muhlstein, S.B. Brown and R.O. Ritchie, Journal of Microelectromechanical Systems 2001, 10, 593.

25. S. Sundararajan and B. Bhushan, Sensors and Actuators A 2002, 101, 338.

26. T. Namazu and Y. Isono, in IEEE Sixteenth Annual International Conference on Micro Electro Mechanical Systems, Jan 19-23 2003, Publ. by IEEE, Piscataway, NJ, USA, 2003, 662 .

27. T. Namazu and Y. Isono, in 17th IEEE International Conference on Micro Electro Mechanical Systems (MEMS): Maastricht MEMS 2004 Technical Digest, Jan 25-29 2004, IEEE, Piscataway, NJ, USA, 2004, 149.

28. A.M. Fitzgerald, R.S. Iyer, R.H. Dauskardt and T.W. Kenny, Journal of Material Research 2002, 17, 683.

29. E.D. Renuart, A.M. Fitzgerald, T.W. Kenny and R.H. Dauskardt, Journal of Material Research 2004, 19, 2635.

30. M. Koskenvuori, T. Mattila, A. Haara, J. Kiihamaki, I. Tittonen, A. Oja, and H. Seppa, Sensors and Actuators A 2004, 115, 23.

31. O. Pierron and C.L. Muhlstein, Journal of Microelectromechanical Systems 2006, 15, 111.

32. W.W. van Arsdell and S.B. Brown, Journal of Microelectromechanical Systems 1999, 8, 319. 
33. H. Kahn, R. Ballarini, R.L. Mullen and A.H. Heuer, Proceedings of the Royal Society of London 1999, 455, 3807.

34. H.Kahn, R.Ballarini, J.J. Bellante and A.H. Heuer, Science 2002, 298, 1215.

35. H. Kahn, R. Ballarini and A.H. Heuer, Current Opinion in Solid State \& Materials Science 2004, 8, 71.

36. S. Suresh, Fatigue of Materials 2nd ed., Cambridge University Press, Cambridge, UK, 1998.

37. O.N. Pierron, C.L. Muhlstein, Fracture and Fatigue of Engineering Materials and Structures 2006, submitted.

38. A.M. Minor, E.T. Lilleodden, M. Jin, E.A. Stach, D.C. Chrzan and J.W. Morris Jr, Phil. Mag. A. 2005, 85, 323.

39. A. Varvani-Farahani, Microsystem Technologies 2005, 11, 129.

40. H. Kapels, R. Aigner and J. Binder, IEEE Transactions on Electronic Devices 2000, 47, 1522.

41. C.L. Muhlstein, S.B. Brown and R.O. Ritchie, Sensors and Actuators A 2001, A94, 177.

42. C.L. Muhlstein, E.A. Stach and R.O. Ritchie, Applied Physics Letters 2002, 80, 1532.

43. C.L. Muhlstein and R.O. Ritchie, International Journal of Fracture 2003, 120, 449.

44. Multi User MEMS Process (MUMPs) foundry; information at http://www.memscap.com/memsrus

45. D. Koester, A. Cowen, R. Mahadevan, M. Stonefield and B. Hardy, PolyMUMPs Design Handbook v10.0 2003.

46. C.L. Muhlstein, R.T. Howe and R.O. Ritchie, Mechanics of Materials 2004, 36, 13.

47. O.N. Pierron and C.L. Muhlstein, International Journal of Fracture 2005, 35, 1. 
48. D.H. Alsem, A.E. Stach, C.L. Muhlstein and R.O. Ritchie, Applied Physics Letters 2005, 86, 041914-1.

49. D.H. Alsem, R. Timmerman, B.L. Boyce, E.A. Stach, J.Th.M. De Hosson and R.O. Ritchie, Journal of Applied Physics 2006, accepted.

50. O.N. Pierron, D.D. Macdonald and C.L. Muhlstein, Applied Physics Letters 2005, 86, 211919.

51. H. Kahn, C. Deeb, I. Chasiotis and A.H. Heuer, Journal of Microelectromechanical Systems 2005, 14, 914.

52. S. Allameh, B. Gally, S. Brown and W.O. Soboyejo, in Materials Research Society Symposium 2001, EE2.3.1.

53. P. Shrotriya, S. Allameh, A. Butterwick, S. Brown and W.O. Soboyejo, in Materials Research Society Symposium 2002, B2.3.1.

54. P. Shrotriya, S. Allameh and W.O. Soboyejo, Mechanics of Materials 2004, 36, 35.

55. W.N. Sharpe, J. Bagdahn, K. Jackson, and G. Coles, Journal of Materials Science 2003, 38,4075 .

56. J. Bagdahn and W.N.J Sharpe, Sensors and Actuators A 2003, 103A, 9.

57. W.N. Sharpe and J. Bagdahn, Mechanics of Materials 2004, 36, 3.

58. A.G. Evans and E.R. Fuller, Metallurgical Transactions A 1974, 5, 27.

59. E. Ferraris, I. Fassi and M. Del Sarto, in $7^{\text {th }}$ Int. Conf. on Thermal, Mechanical and Muliphysics Simulation and Experiments in Micro-Electronics and Micro-Systems EuroSimE 2006.

60. C.D. White, R. Xu, X. Sun and K. Komvopoulos, Proceedings of SPIE: Reliability, Testing, and Characterization of MEMS/MOEMS II 2003, 4980, 63. 
61. T.A. Michalske and S.W. Freiman, Nature 1982, 295, 511.

62. S.J. Dill, S.J. Bennison and R.H. Dauskardt, Journal of the American Ceramic Society 1997, 80, 773 .

63. T. Namazu and Y. Isono, Sensors and Actuators A 2003, 104A, 78.

64. A. Fargeix, G. Ghibaudo and G. Kamarinos, Journal of Applied Physics 1983, 54, 2878.

65. A. Fargeix and G. Ghibaudo, Journal of Applied Physics 1983, 54, 7153.

66. A. Fargeix and G. Ghibaudo, Journal of Applied Physics 1984, 56, 589.

67. E.A. Irene, Journal of Applied Physics 1983, 54, 5416. 


\section{Appendix: Micron-scale fatigue testing methods}

The micron-scale silicon fatigue test results presented in Section 2 and 3 have been obtained using several different testing configurations. In this appendix, we illustrate the increasing variety of testing methods that have been used to study such thin-film fatigue. Currently two major classes of testing systems can be distinguished: (i) on-chip electrical testing systems, where the tested structural film and the electrostatic actuation is integrated onto a MEMS chip (most of these testing systems use electrostatic actuation), and (ii) testing systems where the micron-scale test sample is separated from a larger scale external actuator.

\section{A1: On-chip electrically-actuated loading systems}

The first micron-scale fatigue characterization structure used by Connally and Brown ${ }^{[4,15,16]}$ comprised a micromachined p-type single-crystal silicon cantilever beam (pre-cracked) attached to a rectangular plate allowed to electrostatically resonate in the out-of-plane direction. Van Arsdell and Brown ${ }^{[32]}$ developed a similar fatigue testing procedure for polysilicon, again using electrostatically-actuated devices, but with the difference that inplane rather than out-of-plane resonance was used. Their fatigue characterization structures consisted of a $2 \mu \mathrm{m}$ thick cantilever beam (pre-cracked) attached to a triangular-shaped proof mass fabricated in the MEMSCAP (then MCNC) MUMPs process ${ }^{[44,45]}$. Muhlstein, Brown, and Ritchie (Figure $2^{[24]}$ ) utilized the same design for their single-crystal boron doped silicon testing, although instead of using pre-cracked beams to investigate crack propagation ${ }^{[4,32]}$, they employed a notched cantilever beam (with a $1 \mu \mathrm{m}$ root radius) to permit the investigation of both initiation and growth of small flaws. Muhlstein, Brown, Stach, Alsem and Ritchie ${ }^{[11,41-43,48,49]}$ and Shrotiya, Allameh, Soboyejo and coworkers ${ }^{[12,52-54]}$ also used this resonator 
design for the testing of thin-film polysilicon. Their specimens $\left(2 \mu \mathrm{m}\right.$ thick, $\mathrm{n}^{+}$-type polysilicon, also fabricated in the MUMPs foundry ${ }^{[44,45]}$ ) again consisted of a notch cantilever beam (without pre-crack) attached to a triangular-shaped proof mass that was electrostatically actuated at resonance; displacements were measured using capacitive sensing. In their study [31], Pierron and Muhlstein used $\mathrm{n}^{+}$-type single-crystal silicon (10 $\mu \mathrm{m}$ thick) resonators, fabricated in the MEMSCAP SOIMUMPs process ${ }^{\mathrm{c}}$, again based on the design by Van Arsdell and Brown ${ }^{[32]}$.

Several other resonator designs have been used to investigate thin-film silicon fatigue. Tabib-Azar et al. ${ }^{[18]}$ utilized heavily doped ( ${ }^{+}$-type) micromachined single-crystal silicon cantilever beams (not pre-cracked), which were electrostatically excited at resonance at a frequency of $\sim 6-7 \mathrm{kHz}(R=-1)$. An optical deflection system was used to measure the deflection angle, and hence the displacements (for small deflection angles), of the cantilever beam. Koskenvuori et al. ${ }^{[30]}$ used $10 \mu \mathrm{m}$ thick single-crystal silicon micro-resonators which they actuated in length-extensional mode. The resonators consisted of a $145 \mu \mathrm{m}$ long arm with a resonant frequency $f_{0}=13.1 \mathrm{MHz}$ (electrostatically actuated at $R=-1$ ).

Yet another specimen design was used by Kahn, Ballarini, and Heuer ${ }^{[13,33-35]}$ who developed electrostatically-actuated polysilicon fatigue specimens that offered the unique ability to perform cyclic loading (at resonance) at varying loading ratios $(-3<R<0.5)$, by superposing a DC voltage to an AC voltage. The device consisted of two, large, interdigitated comb drives; one comb drive was free to move in the plane of the structure when subjected to electrostatic actuation. Attached to this comb drive was a notched beam (anchored to the

\footnotetext{
${ }^{\mathrm{c}}$ More information: http://www.memscap.com/memsrus/svcssoirules.html
} 
substrate on one end) with a $1 \mu \mathrm{m}$ root radius notch used for stress concentration (Figure 6). The devices were fabricated from a $5.7 \mu \mathrm{m}$ thick film of polysilicon that was doped with boron. They also used an alternate device consisting of undoped polysilicon coated with $\sim 10$ nm of palladium $(\mathrm{Pd})$ for sufficient conductivity; the tensile residual stress associated with the Pd coating allowed the devices to be driven at resonance, while the displacement was measured optically.

Ferraris et al. ${ }^{[59]}$ also used an electrostatic actuator device which comprised an electrostatic comb driven reciprocal rotor actuator, similar to the design used by White et al.

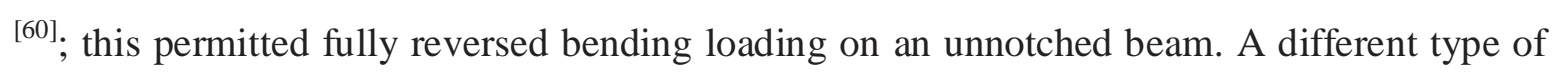
polysilicon actuator was employed by Kapels, Aigner and Binder ${ }^{[40]}$, consisting of an electrically powered thermal actuator. Their actuator consisted of two narrow beams (of different lengths) that expanded due to electrical heating, and a cold plate to which a short beam (the specimen) was attached. A sinusoidal current was used to generate tension-tension cyclic loading $(R=0)$ at a frequency of $1 \mathrm{~Hz}$, and displacements were measured optically.

\section{A2: Externally-actuated loading systems}

An external piezoelectric actuated resonator involving single-crystal silicon resonators was utilized by Tsuchiya and coworkers ${ }^{[19]}$. The test device was bulk micromachined and consisted of a mass supported by four beams (the test specimens) connected with strain gauges that measured the vertical displacement of the mass. The resonant frequency of the device was about $9 \mathrm{kHz}$. The resonator was oscillated using a piezoelectric actuator $(R=-1)$ in a closed-loop configuration that allowed testing at resonance at constant amplitude. Another type of specimen and external actuation method was utilized by Komai, Minoshima, 
and coworkers ${ }^{[21,22]}$, which involved single-crystal silicon cantilever beams. These tests were performed using a specially designed electromagnetic actuator, allowing tension cyclic loading $(R=0.1)$ at a frequency of $0.1 \mathrm{~Hz}$. Displacements were measured using a differential transformer. Ando et al. ${ }^{[23]}$ used a tensile testing method. Their micromachined single crystal device consisted of a tensile specimen attached to a load lever, a pair of torsion bars and the supporting frame. An external load applied perpendicularly to the loading lever resulted in uniaxial loading of the tensile specimen. Cyclic loading was performed at $10 \mathrm{~Hz}$ under displacement control with a stress ratio, $R$, of 0.1 .

Fatigue testing at small dimensions was achieved by Sundurarajan and Bushan ${ }^{[25]}$ who used single-crystal silicon nanometer-scale double clamped beams fabricated from a $\{100\}$ silicon-on-insulator wafer. They employed an AFM to bend the beams while monitoring loads and displacements. Another study using AFM actuation was performed by Namazu and Isono, who employed different types of micron-scale single-crystal silicon specimens ${ }^{[26,27]}$, specifically, nano-scale fixed-fixed beams (width $<1 \mu \mathrm{m}$, thickness $255 \mathrm{~nm}$, length $6 \mu \mathrm{m}$ ) with trapezoid-shape cross-section and various micron-scale specimens for bending and tensile mode testing. Fatigue tests were performed using an AFM (for nano-scale specimens), a nano-indentation tester (for micron-scale bending specimens), or a compact tensile tester manufactured by the authors (for micron-scale tensile specimens). The stress ratio was positive (cyclic tension loading) and the loading frequency ranged from $10 \mathrm{~Hz}$ to $450 \mathrm{~Hz}$.

A very different method was used by Dauskardt, Kenny, Fitzgerald, and coworkers, who utilized single-crystal silicon micromachined specimens with a $150 \mu \mathrm{m}$ thick test section (Figure $3^{[28,29]}$ ). A compression-loaded double cantilever-beam specimen with an external load was used to produce stable controlled-growth tensile crack. Crack growth was measured 
via change in electrical resistance of a thin metal film deposited on the side face of the specimen, with a thin oxide layer in between. Specimens were tested under monotonic loading in both displacement and load control. A sharp pre-crack was initially formed from the blunt notch. Cyclic tests were run at $20 \mathrm{~Hz}$ with an applied sinusoidal waveform and nominal stress ratio $R=0.1$.

Finally, Bagdahn and Sharpe (Figure $17^{[55-57]}$ ) investigated externally actuated microtensile specimens, with applied stresses directly measured using an external load cell. The specimens were loaded with a low voltage piezoelectric actuator for frequencies up to $1 \mathrm{kHz}$, or with a loudspeaker at $6 \mathrm{kHz}$, under zero-tension cyclic loading (i.e., at $R=0$ ). 


\section{LIST OF FIGURE CAPTIONS}

Figure 1: Combined, normalized, applied maximum stress vs. number of cycles to failure $(S$ $N)$ curve for the cyclic fatigue of single-crystal silicon in ambient air. The stress values are normalized with respect to the stress from the test in that particular study that was run at the lowest number of cycles (and therefore in all but one case also with the test run at the highest stress). For the data from Namazu ${ }^{[27]}$ : the open squares are test in bending and the closed squares are test in tension.

Figure 2: Scanning electron micrographs of resonator stress-life fatigue characterization structure. The electrostatic comb drive actuator (A), resonant mass (B), capacitive displacement transducer comb (C), and notched cantilever-beam specimen (D) are shown in an overview on the left. A detail of the notched beam is shown on the right. ${ }^{[24]}$

Figure 3: Schematic illustration of the compression-loaded double cantilever beam specimen. Specimen height is $7.6 \mathrm{~mm}$ with a length of $12 \mathrm{~mm} .^{[28]}$

Figure 4: Fatigue-crack growth data, $\mathrm{d} a / \mathrm{d} N$ vs. $K_{\max }$, in $150 \mu \mathrm{m}$ thick single-crystal silicon (from different load ramps) are compared for cyclic and static fatigue tests. The area marked by the dotted line shows static fatigue test results in $50 \%$ relative humidity. ${ }^{[29]}$

Figure 5: Decrease in resonant frequency, $f_{0}$, during cycling at constant stress amplitude $(2.85$ $\mathrm{GPa})$ in air $\left(30^{\circ} \mathrm{C}\right)$ at various successive relative humidity levels: 50, 25, 50, 25, 50, 40, and $50 \% \mathrm{RH}$. The numbers near the relative-humidity line indicate the average decrease in $f_{0}$ per $10^{9}$ cycles for the particular humidity value. ${ }^{[31]}$

Figure 6: Scanning electron microscopy (SEM) images of a micromachined device for measuring bend strength and fatigue resistance. (a) The electrostatic comb-drive actuator integrated with the fracture mechanics specimen. $(b, c)$ Higher magnification rotated images of 
two single edge-notched fatigue specimens that can be integrated with the actuator; the inset in (b) shows the notch area after testing. (d) Higher magnification rotated image of the measurement scale used for optical displacement detection. ${ }^{[36]}$

Figure 7: Schematic illustration of the mechanism, proposed by Kahn et al., to explain the influence of environment on the fatigue behavior of silicon thin films, In air, native oxide formation or oxide debris accumulation creates local wedges within the wake of newly formed crack surfaces. Under compression loading, the wedge is assumed to create a driving force for further crack extension due to a "cantilever effect". ${ }^{[36]}$

Figure 8: Schematic illustration of the influence of environment on the fatigue behavior of silicon thin films proposed by Kahn et al. Wear debris formed in dry air or vacuum accumulate in the crack wake, leading to crack closure ${ }^{[36]}$

Figure 9: Qualitative weakening/strengthening map showing the influence of the fatigue amplitude and mean stress. ${ }^{[13]}$

Figure 10: Combined, normalized, applied maximum stress vs. number of cycles to failure $(S-N)$ curve for fatigue of polysilicon in ambient air. The stress values are normalized with respect to the stress from the test in that particular study that was run at the lowest number of cycles (and therefore in all but one case also with the test run at the highest stress).

Figure 11: HVTEM images of the notch region in an unthinned, $2 \mu \mathrm{m}$ thick, polycrystalline silicon test sample after high-cycle fatigue. (Left) This image shows enhanced oxidation at the notch root that failed, after $3.56 \times 10^{9}$ e cycles at stress amplitude of $\sigma_{a}=2.26 \mathrm{GPa}$. (Right) This image shows stable cracks, $\sim 50 \mathrm{~nm}$ in length, in the native oxide formed during cyclic fatigue loading; testing of this sample was interrupted after $3.56 \times 10^{9}$ cycles at a stress 
amplitude $\sigma_{a}=2.51 \mathrm{GPa}$. Image was intentionally defocused to facilitate the observation of the cracks. ${ }^{[11]}$

Figure 12: Schematic illustration of the reaction-layer fatigue mechanism for thin-film fatigue at the notch of the polycrystalline silicon cantilever beam: (a) reaction layer (postrelease oxide) on surface of the silicon, (b) localized cyclic stress-assisted oxide thickening at the notch root, (c) moisture-assisted crack initiation in the surface oxide at the notch root, (d) additional thickening and cracking of reaction-layer, and (e) unstable crack growth in the silicon film. ${ }^{[11]}$

Figure 13: Representative damage accumulation in polycrystalline silicon, shown by experimentally measured decrease in resonant frequency, $f_{\text {crack}}$, with cycles during a fatigue test $\left(N_{\mathrm{f}}=2.23 \times 10^{10}\right.$ cycles at $\left.\sigma_{\mathrm{a}}=3.15 \mathrm{GPa}\right)$ and the corresponding computed increase in crack length, $a .^{[11]}$

Figure 14: HVTEM images from failed MUMPs resonator devices. (a) Monotonically fractured specimen in ambient air: no (local) oxide thickening. Because of sample tilt, some contrast in grains at the edge is visible. Only the top transparent part is amorphous; (b) fatigued in ambient air with thickened oxide layer at the notch root (maximum cyclic stress at the notch root: $2.86 \mathrm{GPa}$; number of cycles at failure: $6.28 \times 10^{8}$ ); (c) device after fatigue attempt in vacuo and subsequent single-cycle fracture: no oxide layer thickening (maximum cyclic stress at the notch root during fatigue attempt: $3.29 \mathrm{GPa}$, number of cycles when stopped: $1.14 \times 10^{10}$ ). Also in this case contrast from grains on the edge is visible; only the top amorphous layer is oxide. ${ }^{[48]}$

Figure 15: $S-N$ fatigue data showing polysilicon fatigue resonator devices run in ambient air $\left(\sim 25^{\circ} \mathrm{C}, \sim 35 \% \mathrm{RH}\right)$ in general have longer lives than corresponding devices run at high 
relative humidity $(>95 \% \mathrm{RH})$. No fatigue failures were found in vacuo $\left(2 \times 10^{-5} \mathrm{~Pa}\right)$; the vacuum data points are run-outs. ${ }^{[49]}$

Figure 16: Surface topography evolution showing in a series of AFM surface scans of the area below the notch tip: (a) Before actuation, (b) After the actuation of polysilicon structures for $2 \times 10^{9}$ cycles on a $2 \mu \mathrm{m} \times 2 \mu \mathrm{m}$ scale; (c) and (d) are corresponding images on a $5 \times 5$ $\mu \mathrm{m}$ scale (before and after actuation, respectively), (e) Location of scan area at the vicinity of the notch root of the fatigue resonator (similar design as shown in Figure 2) corresponding to (a)-(d). ${ }^{[12]}$

Figure 17: Scanning electron microscope image of the miniature tensile specimen used in the study of Bagdahn and Sharpe ${ }^{[55-57]}$. The free paddle is attached to an external loading system during the fatigue test.

Figure 18: Stress-lifetime $(S / N)$ curve of thin-film polysilicon tensile specimens during cyclic loading tested with different loading frequencies between 50 and 6,000 $\mathrm{Hz}{ }^{[56]}$ 